\title{
Automatisierte MR-Volumetrie des Bulbus olfactorius
}

\author{
Dissertation \\ zur Erlangung des akademischen Grades
}

doctor medicinae (Dr. med.)

vorgelegt dem Rat der Medizinischen Fakultät der Friedrich-Schiller-Universität Jena

von Niclas Schmitt

geboren am 14.12.1991 in Heidelberg 
Gutachter:

1. Priv.-Doz. Dr. med. habil. Thomas Bitter, Klinik für Hals-, Nasen- und Ohrenheilkunde, Universitätsklinikum Jena

2. Prof. Dr. med. habil. Thomas Hummel, Klinik und Poliklinik für Hals-, Nasenund Ohrenheilkunde, Universitätsklinikum Carl-Gustav-Carus Dresden

3. Prof. Dr. med. habil. Volker Gudziol, Klinik und Poliklinik für Hals-, Nasenund Ohrenheilkunde, Universitätsklinikum Carl-Gustav-Carus Dresden 
Kein Ort in Deutschland würde mir das sein, was Jena und seine Nachbarschaft mir ist, denn ich bin überzeugt, dass man nirgends eine so wahre und vernünftige Freiheit genießt und in so kleinem Umfang so viele vorzügliche Menschen findet.

(Friedrich von Schiller am 6. April 1795) 


\section{$\underline{\text { Inhaltsverzeichnis }}$}

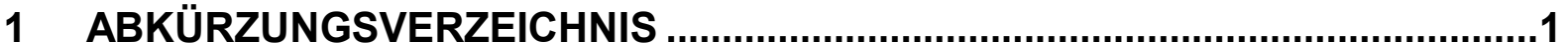

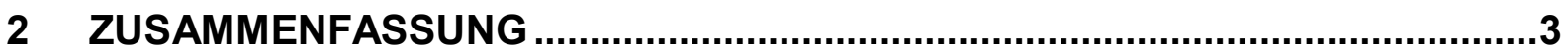

3 EINLEITUNG

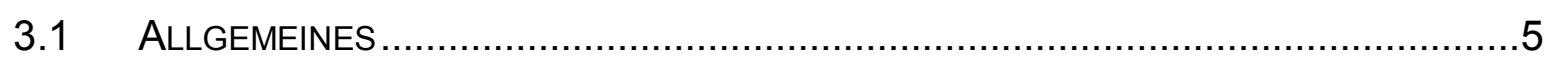

3.2 ANATOMIE UND PHYSIOLOGIE DES OLFAKTORISCHEN SYSTEMS ............................5

3.2.1 Anatomie des Nervus olfactorius ........................................................

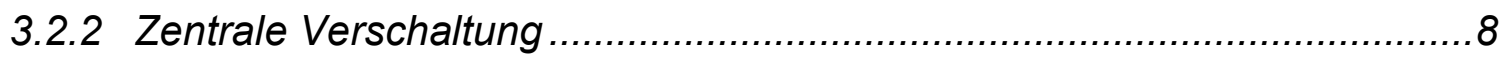

3.2.3 Physiologie des Riechens ..................................................................10

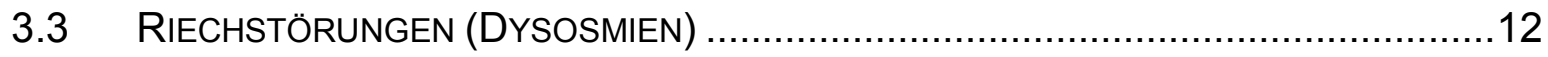

3.3.1 Definitionen von Riechstörungen ....................................................13

3.3.2 Ätiologie und Epidemiologie von Riechstörungen ..................................14

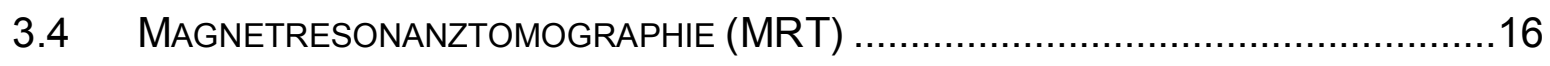

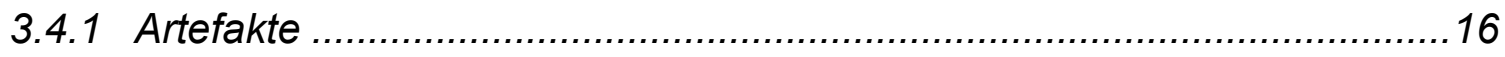

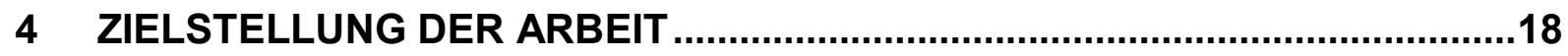

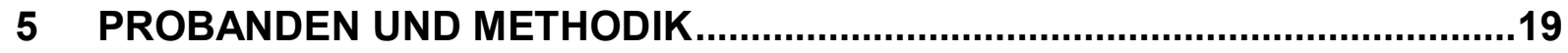

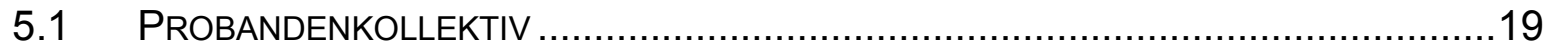

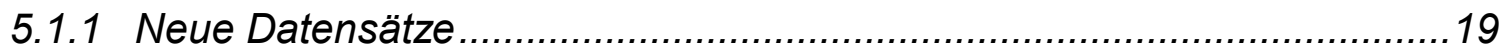

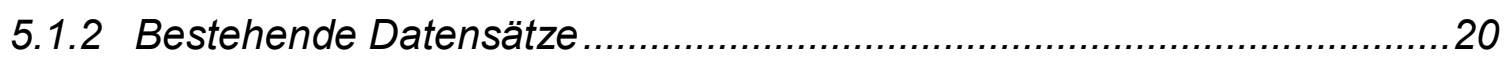

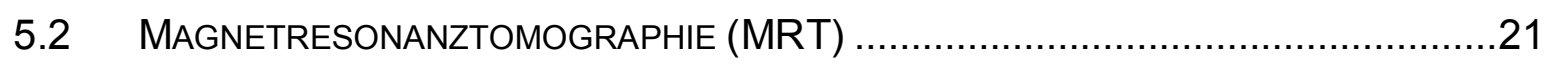

5.2.1 Untersuchungssequenzen - Neue Datensätze......................................21

5.2.2 Untersuchungssequenzen - Bestehende Datensätze.............................21

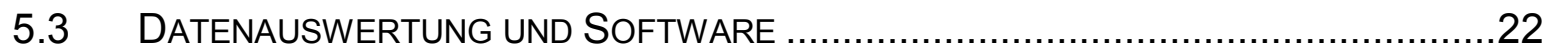

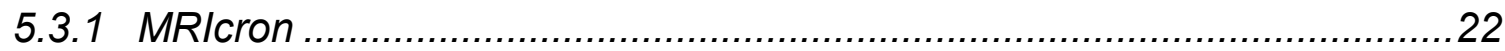

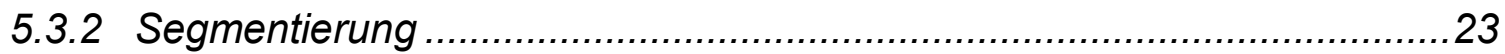

5.3.3 Algorithmus zur automatisierten Volumetrie ........................................24

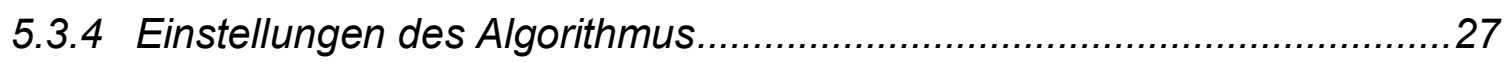

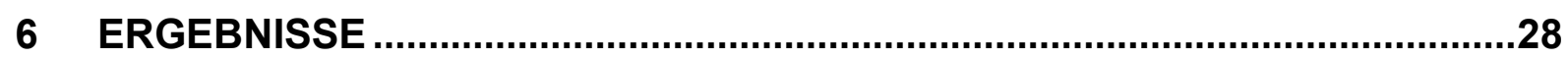

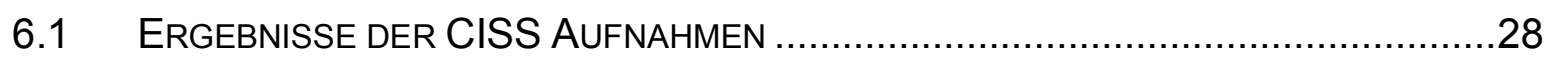

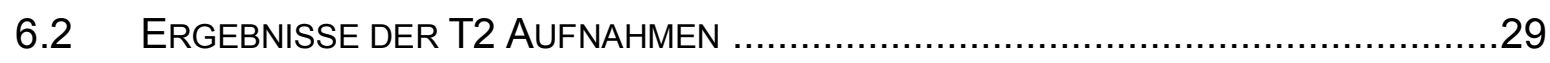

6.3 ERGEBNISSE DER BESTEHENDEN DATENSÄTZE ............................................ 
7 DISKUSSION

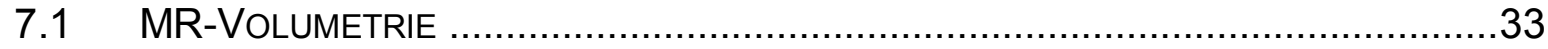

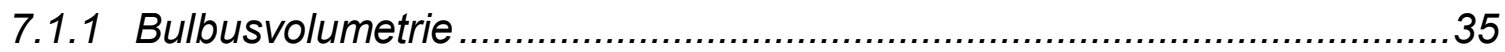

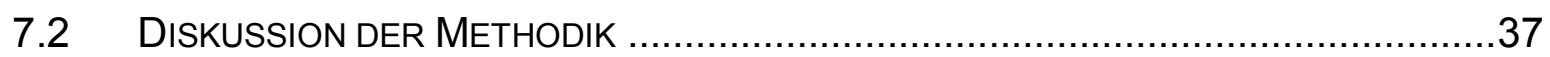

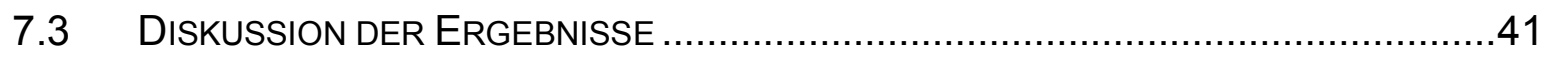

8 SCHLUSSFOLGERUNGEN UND AUSBLICK ...............................................44

$9 \quad$ LITERATUR- UND QUELLENVERZEICHNIS ...................................................

10 ANHANG

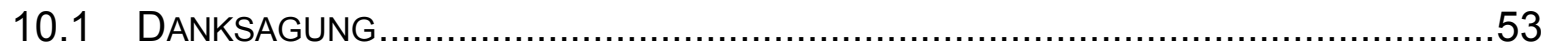

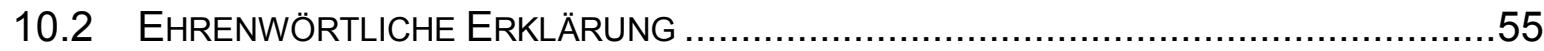




\section{Abkürzungsverzeichnis}

\begin{tabular}{|c|c|}
\hline Abb. & Abbildung \\
\hline AC & Commissura anterior \\
\hline ant. & anterior \\
\hline Aufl. & Auflage \\
\hline BO & Bulbus olfactorius \\
\hline bzw. & beziehungsweise \\
\hline ca. & circa \\
\hline cAMP & Cyclisches Adenosinmonophosphat \\
\hline CISS & Constructive Interference in Steady State MR-Sequenz \\
\hline cMRT & craniale Magnetresonanztomographie \\
\hline CNG & cyclic nucleotide-gated channels \\
\hline d.h. & das heißt \\
\hline etc. & et cetera \\
\hline ICF & Iterative Context Forests \\
\hline $\mathrm{L}$ & links \\
\hline $\mathrm{m}$ & männlich \\
\hline $\mathrm{MHC}$ & Major Histocompatibility Complex \\
\hline $\min$ & Minute \\
\hline $\mathrm{mm}$ & Millimeter \\
\hline MR & Magnetresonanz \\
\hline MRT & Magnetresonanztomographie \\
\hline $\mathrm{ms}$ & Millisekunde \\
\hline N. & Nervus \\
\hline Ncl. & Nucleus \\
\hline NIfTI & Neuroimaging Informatics Technology Initiative \\
\hline o.g. & oben genannt \\
\hline OBPs & odorant binding proteins \\
\hline OECs & olfactory ensheathing cells \\
\hline PC & Commissura posterior \\
\hline $\mathrm{R}$ & rechts \\
\hline ROI & Region of Interest \\
\hline SNR & Signal- zu Rausch-Verhätlnis \\
\hline
\end{tabular}


sog. sogenannt

Syn. Synonym

T2w T2-gewichtete Sequenz

Tab. Tabelle

TE echo time

TO Tractus olfactorius

TR repetition time

TSE Turbo-Spin-Echo MR-Sequenz

W

weiblich

z.B. zum Beispiel

ZNS Zentralnervensystem 


\section{Zusammenfassung}

Der Bulbus olfactorius (BO) gilt als eine der zentralen Stationen im Verlauf der Riechbahn und nimmt als erster synaptischer Umschaltpunkt in der Verarbeitung olfaktorischer Informationen eine wichtige Rolle ein. Zahlreiche Studien konnten eine Korrelation zwischen der Riechfunktion und dem Volumen des Bulbus olfactorius aufzeigen. Auch konnte der Zusammenhang zwischen einer olfaktorischen Beeinträchtigung und dem Auftreten neurodegenerativer Erkrankungen dargestellt werden. Dabei sind besonders die beiden Krankheitsbilder Morbus Alzheimer und Morbus Parkinson hervorzuheben. Beide Erkrankungen zeichnen sich durch eine frühzeitige olfaktorische Beeinträchtigung aus. Diese ist oftmals Jahre vor weiteren Krankheitssymptomen nachweisbar und geht unter anderem mit einer Volumenreduktion des Bulbus olfactorius einher. Zum Nachweis eines solchen Volumenverlustes in vivo ist die Magnetresonanztomographie (MRT) diagnostisches Verfahren der Wahl. Erhobene MR-Aufnahmen des Bulbus olfactorius werden anschließend in einem zeitaufwendigen Segmentationsverfahren manuell aufgearbeitet und volumetrisch vermessen. Unter anderem weil dieses Verfahren einem deutlichen Zeit- und Arbeitsaufwand unterliegt, wird es in der klinischen Routine bisher nicht standardmäßig eingesetzt.

Ziel der vorliegenden Arbeit war daher die Entwicklung eines neuen Verfahrens zur vollautomatisierten Volumetrie des Bulbus olfactorius aus MRT-Datensätzen. Hiermit soll eine schnelle Volumenbestimmung des BO ermöglicht werden, um das Verfahren für die klinische Routine einsetzbar zu machen. Die magnetresonanztomographische Bestimmung der BO-Volumina könnte zukünftig als einfacher Marker zur Verlaufsobjektivierung, Erkennung und Diagnosesicherung entsprechender Krankheitsbilder beitragen.

Es wurden insgesamt 20 MRT-Datensätze unter Anwendung einer Constructive Interference in Steady State- (CISS) und einer T2w TSE-Sequenz an 10 Probanden erhoben. Zusätzlich wurden 20 MRT-Datensätze in CISS-Sequenz aus einem bestehenden Datenpool in die Studie einbezogen. Alle Aufnahmen erfolgten am Universitätsklinikum Jena an einem 3 Tesla MR-Tomographen unter Verwendung einer 64-Kanal-Kopfspule. Die MRT-Datensätze wurden anschließend sowohl manuell unter Verwendung des Computerprogramms MRIcron (University of South Carolina) als auch automatisiert segmentiert und die BO-Volumina bestimmt. Das automatisierte Verfahren setzte einen am Lehrstuhl für Digitale Bildverarbeitung der Fakultät für 
Mathematik und Informatik an der Friedrich-Schiller-Universität Jena entwickelten Algorithmus ein. Dieser wurde unter Anwendung einer einheitlichen Region of Interest (ROI) von 100 x 100 [Pixel] für alle MRT-Datensätze angewandt. Die quantitativen Resultate zeigen je nach Aufnahmesequenz und -einstellungen, verwendetem MRTScanner und festgelegten Algorithmuseinstellungen unterschiedlich starke Abweichungen der automatisierten von den manuellen Messwerten. Im direkten Vergleich wurden die Bulbi bei der automatisierten Volumenmessung tendenziell als zu groß erkannt. Die geringste Abweichung der automatisierten von den manuellen Messwerten, konnte mit den neu erhobenen MRT-Datensätzen in der CISS-Sequenz erzielt werden. Die qualitativen Eindrücke der Pilotstudie zeigen sehr gute Resultate. Sie stellen eindrücklich dar, dass trotz der geringen Größe des Bulbus olfactorius eine genaue und zugleich automatisierte Segmentierung dieser Struktur möglich ist.

Im Gegensatz zur manuellen Volumenbestimmung besitzt die vollautomatisierte Technik - aufgrund ihres geringen Zeitaufwandes und der Untersucherunabhängigkeit - das Potential, zukünftig in die klinische Routine implementiert zu werden. Der Einsatz einer größeren Anzahl an MRT-Datensätzen verschiedener Probanden zum Training des selbstlernenden Algorithmus, könnte Ergebnisabweichungen der automatisierten von der manuellen Volumetrie weiter minimieren. Hierfür sowie zur Evaluierung der klinischen Einsetzbarkeit des Verfahrens ist eine Studie unter Einschluss eines größeren Probandenkollektivs notwendig. 


\section{Einleitung}

\subsection{Allgemeines}

Der Mensch besitzt fünf verschiedene Sinnesmodalitäten. Hierzu zählen Sehen, Hören, Riechen, Schmecken und Fühlen (Handwerker und Schmelz 2010). Der Geruchssinn stellt dabei einen der komplexesten Sinne dar und ist aus phylogenetischer Sicht zugleich eines der ältesten Sinnessysteme des Menschen (Albrecht und Wiesmann 2006). Im Gegensatz zu vielen Tieren, besitzt der Mensch ein weitaus schwächer ausgeprägtes Riechvermögen. Dies ist vor allem auf eine geringere Anzahl olfaktorischer Neurone zurückzuführen. Aus diesem Grund werden Menschen als Mikrosmatiker und Tiere wie z.B. der Hund als Makrosmatiker bezeichnet (Albrecht und Wiesmann 2006). Die biologische Bedeutung olfaktorischer Sinneseindrücke liegt vor allem in der Erkennung von verdorbenen Nahrungsmitteln und Gefahrenstoffen wie Rauch oder Toxinen (Doty 2009, Hatt 2010, Reed und Knaapila 2010). Der Geruchssinn hat einen großen Einfluss auf Appetit, Essverhalten und die Einleitung von Verdauungsreflexen (kephale Verdauungsphase, Speichel-, Magensaft- und Pankreassekretion) (Mattes et al. 1990, Aschenbrenner et al. 2008, Frings und Müller 2012). Ebenso konnten Auswirkungen auf die Partnerwahl, Sexualverhalten, zwischenmenschliche Kommunikation und soziale Beziehungen dem Geruchsinn zugeordnet werden (Herz und Cahill 1997, Hatt 2010, Stevenson 2010). Dieses Verhalten ist vor allem auf den genetisch determinierten Eigengeruch zurückzuführen, welcher eng mit dem Haupthistokompatibilitätskomplex (MHC) gekoppelt ist (Hatt 2010). Besteht eine Störung des Geruchssinns, wird dies als Dysosmie bezeichnet. Die Beeinträchtigung kann unterschiedlich stark ausgeprägt von einer Minderung (Hyposmie) bis hin zum vollständigen Verlust des Riechvermögens (Anosmie) - und von verschiedener Genese sein.

\subsection{Anatomie und Physiologie des olfaktorischen Systems}

Der Mensch ist in der Lage einige tausend verschiedene Gerüche zu unterscheiden. Dabei können neben dem olfaktorischen System weitere sensorische Systeme, wie das trigeminale- und gutstatorische System, an der Wahrnehmung beteiligt sein (Frings und Müller 2012). 


\subsubsection{Anatomie des Nervus olfactorius}

Der Nervus olfactorius ist der I. Hirnnerv. Es handelt sich um einen speziellviszerosensiblen Nerv, welcher sich aus feinen Fasern, den Fila olfactoria, zusammensetzt (Trepel 2012). Diese Nervenfasern nehmen ihren Ursprung in der ca. $5 \mathrm{~cm}^{2}$ großen, bräunlich gefärbten, Regio olfactoria. Sie befindet sich auf der oberen Nasenmuschel, am Nasendach und einer kleinen Fläche am Nasenseptum. Auch in ihrem histologischen Aufbau ist sie deutlich von der umgebenden Nasenschleimhaut abzugrenzen (Aumüller 2010, Frings und Müller 2012).

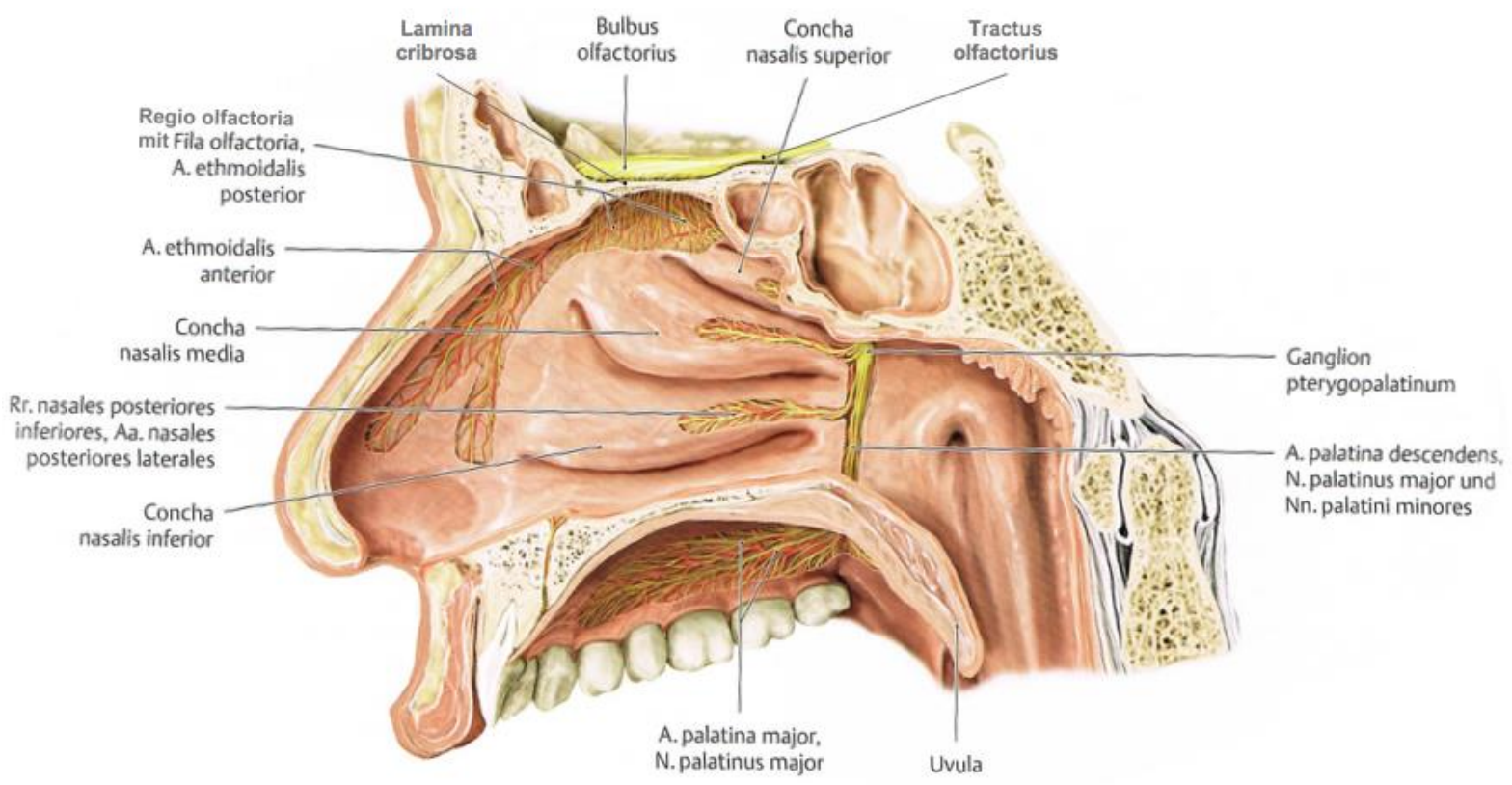

Abb. 1: Paramediansagittalschnitt, Schleimhaut zum Teil entfernt, rechte laterale Nasenwand, Ansicht von links (Schünke et al. 2009 und eigene Überarbeitung.).

Die Riechschleimhaut besteht aus einem relativ hohen, mehrreihigen Epithel und der darunter liegenden Lamina propria. Das Epithel enthält vier Zelltypen: Sinneszellen, Stützzellen, Basalzellen, Mikrovillizellen sowie intra- oder subepithelial liegende Bowman-Drüsen (Mense 2010, Lüllmann-Rauch 2012). Die Bowman-Drüsen oder auch Glandulae olfactoriae sind tubuloalveoläre Drüsen, welche für die Produktion von Riechschleim verantwortlich sind. Diese Schleimschicht liegt dem Riechepithel direkt auf und dient vor allem dessen Spülung wie auch der Bindung flüchtiger Odorantien (Lüllmann-Rauch 2012).

Bei den ca. 20 Millionen Riechsinneszellen handelt es sich um primäre Sinneszellen vom bipolaren Zelltyp (Mense 2010, Rassow 2012). Sie liegen eingebettet zwischen 
Stützzellen und entsenden nach apikal einen dendritischen Fortsatz, der sich am Ende zu einem dendritischen Kolben verdickt. Von diesem Kolben entspringen mehrere - im Riechschleim liegende - Zilien, welche den Ursprung der olfaktorischen Transduktion ausmachen (Lüllmann-Rauch 2012). Die Lebensdauer der Sinneszellen beträgt nur etwa vier bis acht Wochen. In fortwährendem Zyklus regenerieren sich diese jedoch wieder vollständig aus Basalzellen (Rassow 2012). Bemerkenswert an diesem Vorgang ist, dass die neu aussprossenden Axone ihren Weg zu den jeweils richtigen Zielneuronen im ZNS finden. Nach derzeitigem Kenntnisstand ist dieses Geschehen einmalig im neuronalen System des Säugers (Lüllmann-Rauch 2012).

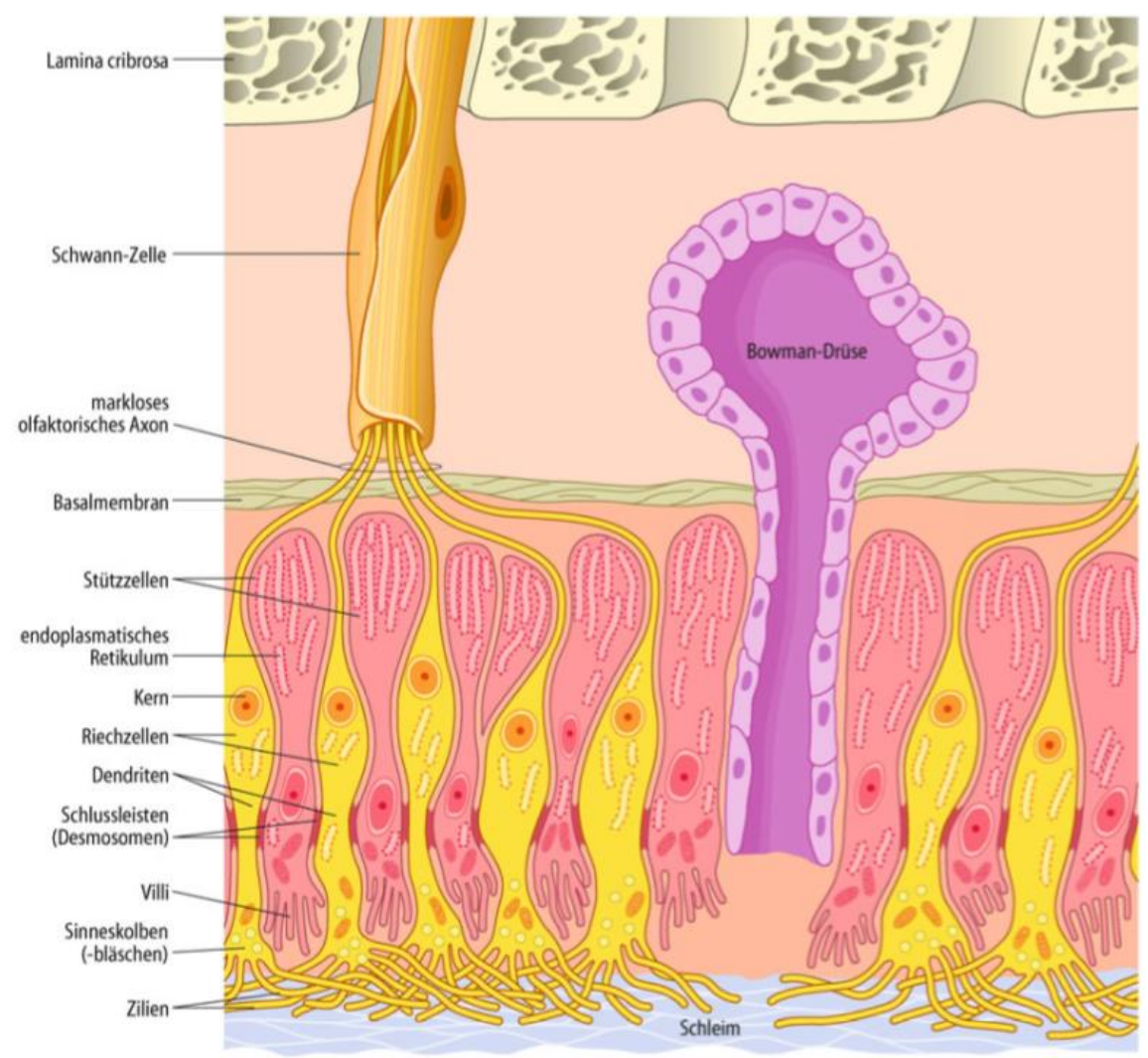

Abb. 2: Histologischer Aufbau der Regio olfactoria mit Riechepithel und Fila olfactoria (Lenarz und Boenninghaus 2012).

Im weiteren Verlauf nach proximal, werden die marklosen Axone der Sinneszellen (1. Neuron der Riechbahn) von olfactory ensheathing cells (OECs) zu Faserbündeln, den Fila olfactoria, zusammengefasst (Chen et al. 2014). Auf jeder Nasenseite finden sich medial 12-16 und lateral 12-20 Fila, die in der Schleimhaut nach kranial verlaufen. Diese durchtreten die Lamina cribrosa im Bereich des frontobasalen Schädels durch etwa 40 kleine Perforationen und gehen somit aus der Nasenhöhle in das Schädelinnere über. Die vom Os ethmoidale gebildete Lamina cribrosa besitzt auf 
jeder Seite eine Vertiefung, die sog. Fossa olfactoria. In dieser liegt auf beiden Seiten der Bulbus olfactorius, zu welchem die jeweils ipsilateralen Fila olfactoria ziehen (Albrecht und Wiesmann 2006, Mense 2010).

\subsubsection{Zentrale Verschaltung}

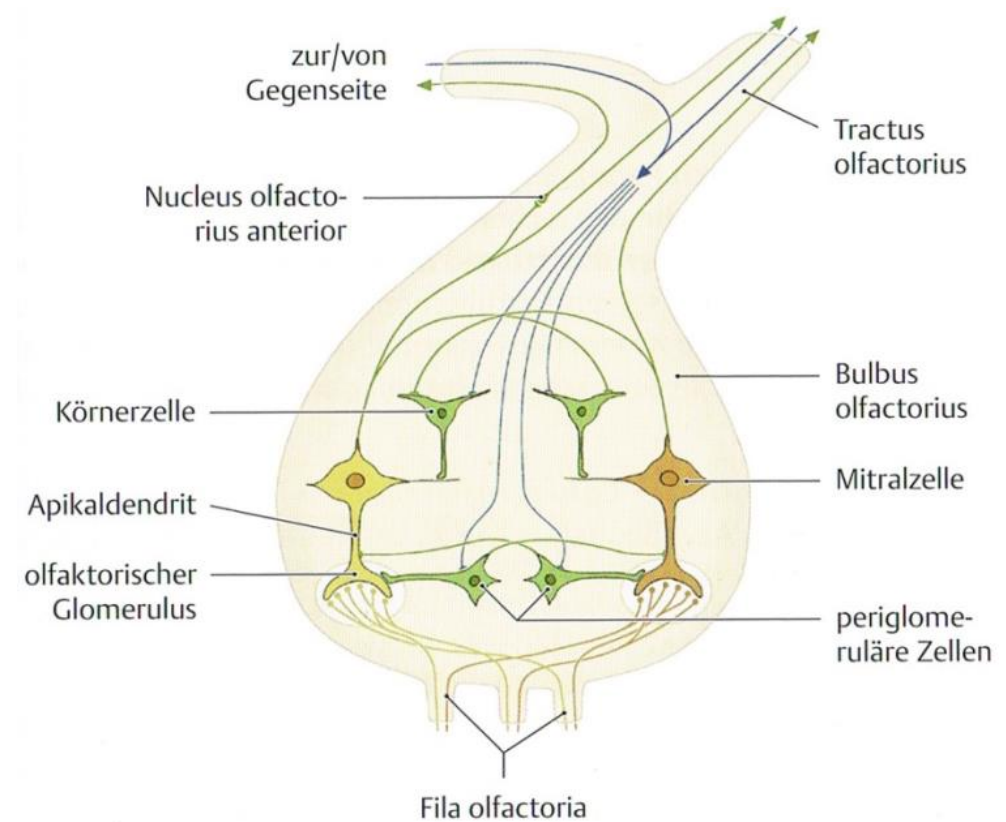

Abb. 3: Verschaltungen in einem Bulbus olfactorius (Schünke et al. 2009).

Der Bulbus olfactorius ist Teil des Paläocortex, dem phylogenetisch ältesten Teil der Großhirnrinde. Er wird nach neuroanatomischen Kriterien als primärer olfaktorischer Kortex bezeichnet und stellt die erste Station der synaptischen Verarbeitung der olfaktorischen Information dar (Mense 2010, Trepel 2012). Beide Bulbi olfactorii zeigen, wie für kortikale Gebiete des ZNS typisch, bereits eine laminare Schichtung. Dabei werden folgende Schichten unterschieden (Witt und Hansen 2008):

- Schicht der olfaktorischen Axone

- Schicht der Glomeruli

- äußere plexiforme Schicht

- Schicht der Mitral-/Büschelzellen

- innere plexiforme Schicht

- Körnerzellschicht 
Die Bulbi enthalten Mitral- und Büschelzellen (2. Neuron der Riechbahn) sowie periglomeruläre Interneurone und Körnerzellen mit teils hemmenden Einflüssen. Die Mitral- und Büschelzellen besitzen apikale Dendriten, an denen die Axone der primären Sinneszellen Synapsen ausbilden. Dendrit und Synpase bilden gemeinsam die olfaktorischen Glomeruli. Aufgrund stark ausgeprägter Topie, gehen Axone von Sinneszellen mit gleichem Rezeptorprotein, nur mit einer oder nur ganz wenigen Mitral-/Büschelzellen, Bindungen zu Glomeruli ein. Die basal liegenden Axone der Mitral- und Büschelzellen formieren sich zum Tractus olfactorius, in welchem sie größtenteils zum olfaktorischen Kortex, aber auch anderen Kerngebieten des ZNS verlaufen (Mense 2010, Schünke et al. 2009).

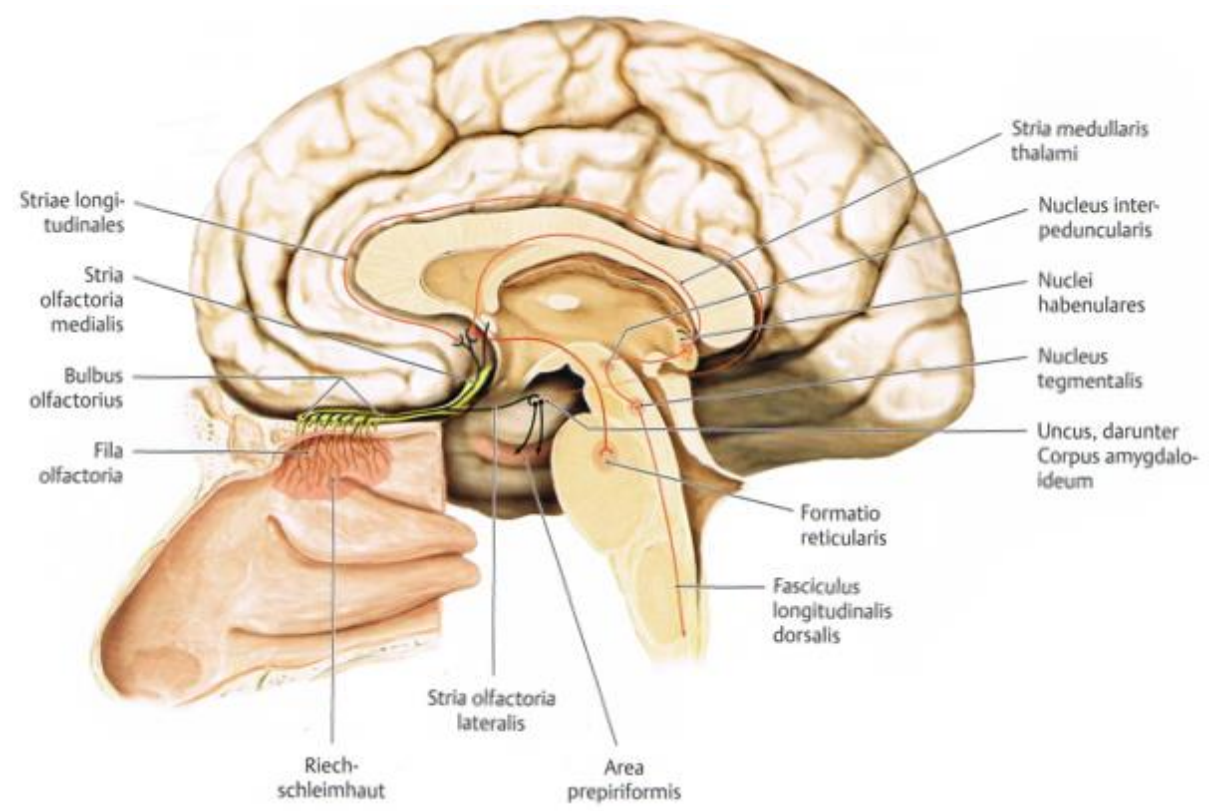

Abb. 4: Strukturen des medialen und lateralen Weges innerhalb der Riechbahn im Mediansagittalschnitt (Schünke et al. 2009).

Als zentrale Ader der Riechbahn zu sekundären olfaktorischen Strukturen gilt der Tractus olfactorius lateralis. Dieser liegt lateral des Gyrus rectus im Sulcus olfactorius an der Unterseite des Frontalhirns. Die in gängigen anatomischen Lehrbüchern und Abbildung 4 dargestellte Teilung vor der Substantia perforata in Stria olfactoria medialis und Stria olfactoria lateralis entstammen Befunden von Makrosmatikern (z.B. Igel oder Ratte) und ist beim Menschen nicht nachweisbar (Sakamoto et al. 1999). Der einzig verbleibende Projektionsweg vom Bulbus olfactorius in nachgeordnete Strukturen des ZNS ist somit der Tractus olfactorius lateralis (Witt und Hansen 2008). Ausnahme bildet ein Hauptast des Tractus olfactorius, welcher in der vorderen 
Kommissur zu dem BO der kontralateralen Hirnseite kreuzt. Dieser macht kontralateral einen Teil der hemmenden Efferenzen für die ipsilateral verlaufenden Axone der Mitralund Büschelzellen aus. Ipsilaterale Körnerzellen und Interneurone hemmen gleichzeitig die Aktivität ipsilateraler Mitral- und Büschelzellen. Diese Verschaltung ermöglicht es, dass weniger Sinneseindrücke nach zentral gemeldet werden und eine stärkere Kontrastbildung zur genaueren Geruchswahrnehmung gefördert wird (Schünke et al. 2009). Das in Abbildung 5 dargestellte Schaubild gibt einen Überblick über die zentralnervösen Projektionen der olfaktorischen Neurone.

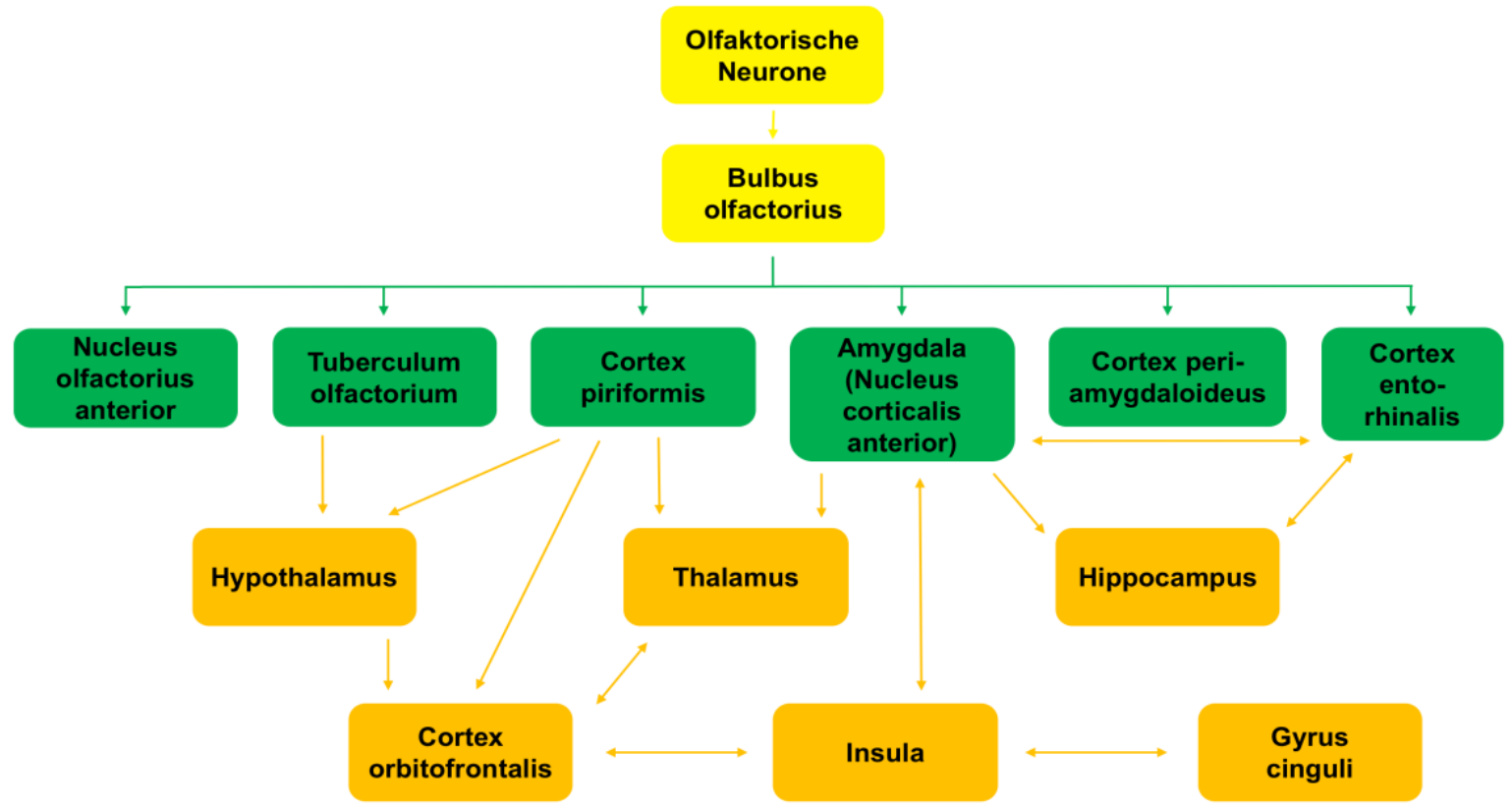

Abb. 5: Überblick über die zentralnervösen Projektionen der olfaktorischen Neurone (Albrecht und Wiesmann 2006)

\subsubsection{Physiologie des Riechens}

Bei allen natürlich vorkommenden Düften handelt es sich um Duftgemische. Der Mensch ist in der Lage etwa 10.000 verschiedene Düfte zu unterscheiden. Bereits 1952 klassifizierte Amoore 7 Geruchsqualitäten/Basisgerüche, welche bis heute Gültigkeit besitzen (Hatt 2010).

Hierzu zählen:

- blumig

- ätherisch

- schweißig 
- moschusartig

- kampferartig

- faulig

- stechend

Im menschlichen Genom kodieren zahlreiche funktionelle Gene für etwa 300 bis 350 Dufstoffrezeptoren, wobei jede Riechzelle nur einen oder wenige Rezeptortypen exprimiert (Malnic et al. 2004, Hatt 2010, Frings und Müller 2012). Diese Duftstoffrezeptoren unterliegen keiner großen Spezifität, sondern lassen sich vielmehr durch mehrere unterschiedliche Duftstoffe aktivieren (Malnic et al. 1999, Malnic et al. 2004, Frings und Müller 2012). Gleichzeitig ist auch ein einzelnes Duftmolekül in der Lage, an eine Vielzahl unterschiedlicher Duftstoffrezeptoren zu binden (Malnic et al. 1999).

Die - durch die Atmung - zur Regio olfactoria transportierten Duftstoffe, werden dort zunächst an olfaktorische Bindungsproteine (OBPs) in der Schleimschicht gebunden. Neben den OBPs gewährleisten zahlreiche weitere Proteine im Mucus mit antioxidativen, antiinflammatorischen, antimikrobiellen und metabolischen Eigenschaften, die normale Funktion des Geruchssinns (Briand et al. 2002, Damm 2007, Debat et al. 2007). Kommt es an den Zilien zu einem Kontakt zwischen Duftstoff und Rezeptor, wird eine Transduktionskaskade ausgelöst. Das Duftstoffsignal wird zunächst verstärkt und anschließend in einen elektrischen Impuls umgewandelt (Frings und Müller 2012).

Die Rezeptoren des olfaktorischen Systems gehören zu der Superfamilie der GProtein-gekoppelten Rezeptoren und bestehen aus sieben transmembranären Domänen (Schild und Restrepo 1998). Bei Bindung eines Duftmoleküls an den spezifischen Rezeptor, wird ein Golf-Protein stimuliert. Dieses wiederum aktiviert das Enzym Adenylatzyklase, welches zur Bildung des Botenstoffes zyklisches Adenosinmonophosphat (cAMP) führt. Das cAMP bindet direkt an lonenkanäle (CNGKanäle) und macht diese permeabel für ein- und zweiwertige Kationen. Die Aktivierung eines einzigen Rezeptorproteins durch ein Duftmolekül kann 1000 bis 2000 solcher cAMP-Moleküle bilden und entsprechend viele lonenkanäle öffnen (Hatt 2010). Dies erklärt die teilweise sehr niederen Schwellenwerte für bestimmte Duftstoffe. Die aus 
dem Mucus in die Zelle einströmenden $\mathrm{Ca}^{2+}$-Ionen binden an $\mathrm{Ca}^{2+}$-aktivierte Chloridkanäle, die wiederum den $\mathrm{Cl}^{-}$-Fluss aus den Zilien zur Folge haben. Dieser Vorgang bewirkt eine Depolarisation, das sog. Rezeptorpotential, welches schließlich Aktionspotentiale auslöst (Kurahashi und Yau 1993, Schild und Restrepo 1998, Hatt 2010, Frings und Müller 2012).

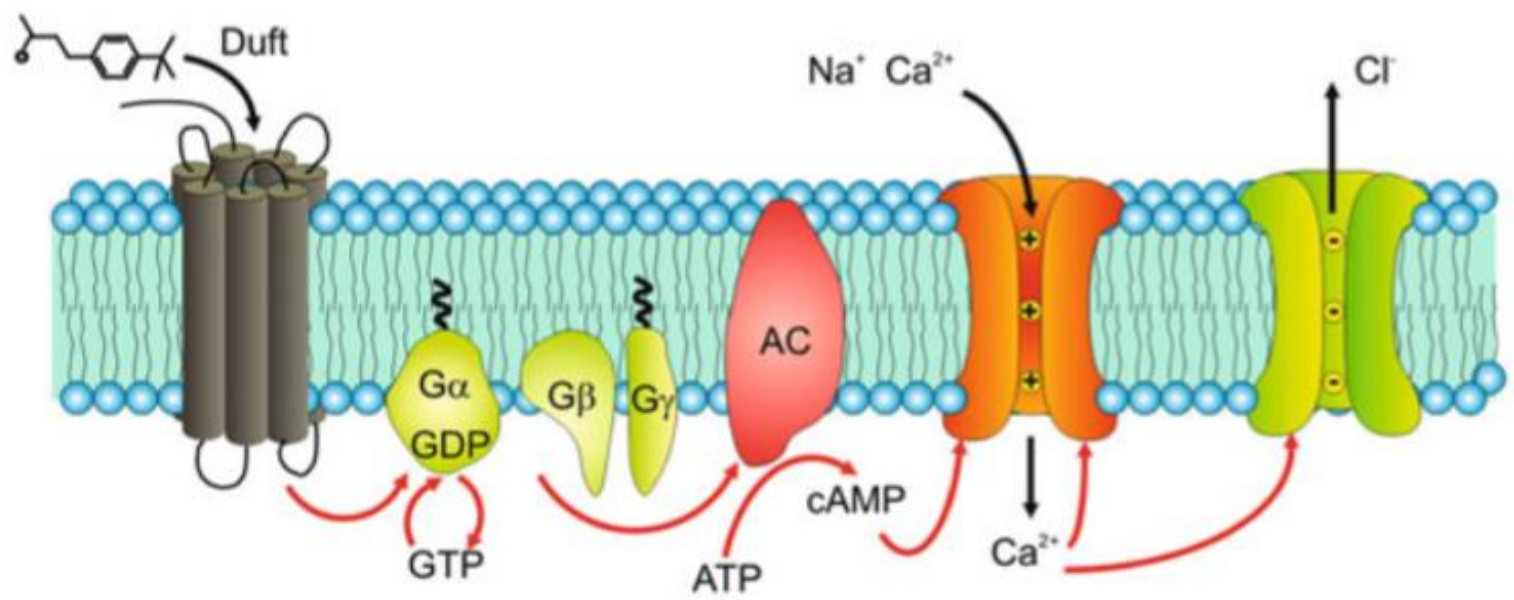

Abb. 6: Schema der Transduktionskaskade in Riechzellen (Hatt 2010).

Duftstoffgemische, bestehend aus bis zu mehreren tausend Einzelkomponenten, binden mit unterschiedlich starker Affinität an eine Vielzahl von Rezeptoren. Dies führt je nach Duft, zu einem spezifischen Muster an aktivierten Duftrezeptoren. Zusätzlich wird das Aktivierungsmuster durch verschiedenste Hemm- und Aktivierungsprozesse beeinflusst. Es wird davon ausgegangen, dass die Geruchswahrnehmung eine Interpretation des Aktivierungsmusters von vielen peripheren sensorischen Neuronen darstellt (Buck 1996, Araneda et al. 2000).

\subsection{Riechstörungen (Dysosmien)}

Erkrankungen des Riechsinns sind weit verbreitet. Alleine im Jahr 2004 wurden an deutschen Kliniken für Hals-, Nasen- und Ohrenheilkunde etwa 79.000 Patienten mit Riechstörungen vorstellig. Niedergelassene Fachärzte sowie Kliniken und Praxen anderer Fachrichtungen (Neurologie, Psychiatrie) wurden hierbei nicht eingeschlossen (Damm et al. 2004). Aufgrund des demographischen Wandels (Nowossadeck 2013) wie auch der Zunahme von Riechstörungen mit steigendem Alter (Hüttenbrink et al. 2013), ist auch in Zukunft von einem weiteren Inzidenz-Anstieg der Riechstörungen auszugehen. 
Betroffene Patienten berichten von zahlreichen Schwierigkeiten im alltäglichen Leben sowie von einem hohen $\mathrm{Maß}$ an persönlicher und interpersoneller Unsicherheit (Hummel und Nordin 2005). Besonders Frauen scheinen durch diese Beeinträchtigung stärker belastet zu sein als Männer (Frasnelli und Hummel 2005). Zu den Hauptbeschwerden zählen ein veränderter Appetit, Stimmungsschwankungen, das Essen verdorbener Lebensmittel, die mangelnde Wahrnehmung des eigenen Körpergeruchs und Schwierigkeiten im Arbeitsumfeld (Temmel et al. 2002). Ingesamt geht eine Beeinträchtigung des Geruchssinns mit einem erheblichen Verlust an Lebensqualität einher (Seo et al. 2009).

Wie in Kapitel 3.2.3 „Physiologie des Riechens“ bereits beschrieben, handelt es sich bei Düften stets um Gemische verschiedener (Duft-)Stoffe. Oftmals enthalten diese Gemische zusätzliche Komponenten, welche auch über andere Sinnessysteme wahrgenommen werden können (Lenarz und Boenninghaus 2012). Das sind zum einen Trigeminusreizkomponenten, welche über den Nervus trigeminus (Hirnnerv V.) wahrgenommen werden (Frasnelli et al. 2007). Zum anderen sind es Geschmackskomponenten, welche über den Nervus facialis (Hirnnerv VII.), den Nervus glossopharyngeus (Hirnnerv IX.) und Nervus vagus (Hirnnerv X.) wahrgenommen werden (Frings und Müller 2012). Somit bleibt auch nach Beeinträchtigung oder Ausfall des Riechvermögens oftmals ein Teil der Wahrnehmung erhalten.

Therapeutisch exisitieren eine Vielzahl verschiedener Ansätze mit dem Ziel der Verbesserung oder Normalisierung des Riechvermögens. Diese bestehen je nach Ursache der Riechstörung in der Anwendung medikamentöser, chirurgischer und sonstiger Verfahren (Riechtraining, Akupunktur, homöopathische Therapie, etc.).

\subsubsection{Definitionen von Riechstörungen}

Dysosmie ist ein Oberbegriff für verschiedene Störungen der olfaktorischen Wahrnehmung. Es lassen sich im Allgemeinen zwei Gruppen von Riechstörungen unterscheiden: die quantitative und qualitative Dysosmie mit ihren jeweiligen Entitäten. Quantitative Störungen entstehen durch eine Verminderung bzw. Aufhebung oder durch eine Verstärkung (deutlich seltener) von Geruchswahrnehmungen. Qualitative Riechstörungen beruhen auf einer veränderten, verfälschten oder halluzinatorischen Geruchswahrnehmung (AWMF 2016). 


\begin{tabular}{|c|c|c|}
\hline $\begin{array}{l}\text { Riechstörung } \\
\text { (Dysosmie) }\end{array}$ & & Definition \\
\hline \multirow[b]{4}{*}{ Quantitativ } & Hyperosmie & übernormale Funktion \\
\hline & Normosmie & normale Empfindlichkeit \\
\hline & Hyposmie & verminderte Empfindlichkeit \\
\hline & Anosmie & $\begin{array}{l}\text { Komplette Anosmie: vollständiger Verlust des } \\
\text { Riechvermögens; kein Restriechvermögen } \\
\text { nachweisbar } \\
\text { Funktionelle Anosmie: sehr deutliche Einschränkung } \\
\text { des Riechvermögens, beinhaltet sowohl den } \\
\text { kompletten Verlust als auch das Vorhandensein einer } \\
\text { geringen Restwahrnehmung; eine sinnvolle Nutzung } \\
\text { des Riechsinnes im Alltag ist nichtmehr möglich } \\
\text { Spezifische Anosmie: deutlich verminderte Sensibilität } \\
\text { gegenüber einem bestimmten Duftstoff bzw. einer } \\
\text { Duftstoffgruppe bei ansonsten normalem } \\
\text { Riechvermögen; die spezifische Anosmie ist ohne } \\
\text { pathologische Bedeutung (Croy et al. 2015) }\end{array}$ \\
\hline \multirow{3}{*}{ Qualitativ } & Parosmie & $\begin{array}{l}\text { veränderte Wahrnehmung von Gerüchen in Gegenwart } \\
\text { einer Reizquelle }\end{array}$ \\
\hline & $\begin{array}{c}\text { Phantosmie } \\
\text { (=Geruchshalluzionation) }\end{array}$ & $\begin{array}{l}\text { wahrnehmung von Gerüchen in Abwesenheit einer } \\
\text { Reizquelle }\end{array}$ \\
\hline & Olfaktorische Intoleranz & $\begin{array}{l}\text { übersteigerte subjekive Empfindlichkeit gegenüber } \\
\text { Duftstoffen bei normaler oder sogar verminderter } \\
\text { olfaktorischer Sensitivität }\end{array}$ \\
\hline
\end{tabular}

Tab. 1: Übersicht über die quantitativen und qualitativen Veränderungen des Riechvermögens (AWMF 2016)

\subsection{2 Ätiologie und Epidemiologie von Riechstörungen}

Pathologien des Riechvermögens können durch eine Vielzahl unterschiedlicher Ursachen bedingt sein. Man geht davon aus, dass etwa 5\% der Bevölkerung an einer (funktionellen) Anosmie leiden (Hummel und Heckmann 2009, Hüttenbrink et al. 2013). Bereits viele Patienten im Alter von 45 bis 65 Jahren sind betroffen, wobei die Inzidenz mit steigendem Alter zunimmt (Hüttenbrink et al. 2013). Die höchste Inzidenz ist in der Altersgruppe der über 65-Jährigen zu finden. Eine sogar mehr als 50\%ige Inzidenz ausgeprägter Riechstörungen zeigt sich bei den über 80-Jährigen (Hummel und Heckmann 2009). Für den deutschsprachigen Raum existieren bis heute diesbezüglich jedoch keine gesicherten epidemiologischen Daten. 
Ätiologisch können Riechstörungen eine Vielzahl verschiedener Ursachen zugrunde liegen. Der größte Anteil der von HNO-Kliniken behandelten Patienten entfällt mit 72\% auf Dysosmien sinunasaler Genese (Entzündungen der Nase bzw. Nasennebenhöhlen, respiratorische Störungen). Die übrigen $28 \%$ entfallen auf nichtsinunasale Ursachen (postviral, idiopatisch, Schädelhirntrauma, iatrogen, toxisch, angeboren). Die Zahlen beziehen sich auf eine Umfrage an 200 HNO-Kliniken in Deutschland, Österreich und der Schweiz aus dem Jahr 2000 (Damm et al. 2004).
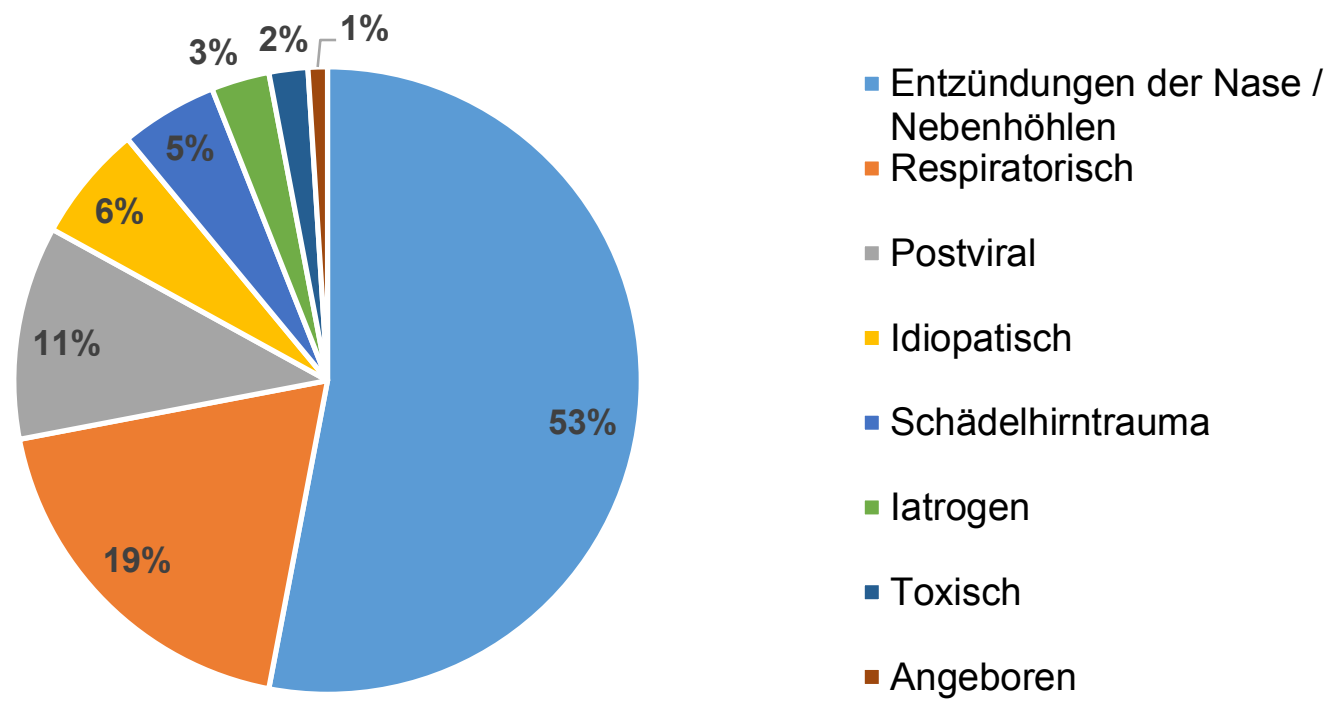

Abb. 7: Häufigkeit und Ursachen von Riechstörungen (Damm et al. 2004).

Nicht erwähnt werden in Zusammenhang mit dieser Studie, Riechstörungen mit klar erkennbarer internistischer, neurologischer oder psychiatrischer Genese. Zwar ist die genaue Pathophysiologie für die Entstehung der Geruchsempfindungsstörung bei den meisten Erkrankungen noch nicht ausreichend untersucht, doch machen auch diese einen gewissen Anteil an Usachen aus. Im Folgenden sind einige häufige Erkrankungen genannt, welche mit Geruchsempfindungsstörungen einhergehen:

internistisch:

- Typ-2-Diabetes (Weinstock et al. 1993, Gouveri et al. 2014)

- Schilddrüsenunterfunktionen (Gunbey et al. 2015) neurologisch:

- Morbus Alzheimer (Mesholam et al. 1998, Peters et al. 2003)

- Morbus Parkinson (Ansari und Johnson 1975, Doty 2012)

- Multiple Sklerose (Lucassen et al. 2016) 
psychiatrisch:

- Depressionen (Pause et al. 2001)

- Schizophrene Psychosen (Moberg et al. 1999)

Die in Zukunft zu erwartende Inzidenz- und Prävalenz-Zunahme von Riechstörungen macht die weitere Erforschung pathogenetischer Mechanismen unentbehrlich.

\subsection{Magnetresonanztomographie (MRT)}

Bei der Magnetresonanztomographie (Kernspintomographie, MRT) handelt es sich um ein bildgebendes Verfahren zur Erzeugung von Schnittbildern in einer frei wählbaren Raumebene ohne Verwendung von Röntgenstrahlung (Hünerbein 2011). Die physikalische Grundlage der Bilderzeugung ist die Darstellung von Wasserstoffmolekülen. In einem vom Magnetresonanztomographen erzeugten, homogenen Magnetfeld sowie hochfrequenten Radiowellen werden induzierte Signale erfasst und entsprechend ihrer Lokalisation zu zweidimensionalen Bildern rekonstruiert. Sie dient vor allem in der medizinischen Diagnostik zur Darstellung von Struktur und Funktion verschiedener Organe und Gewebe. Aufgrund des hohen Weichteilkontrasts eigenet sie sich besonders zur Beurteilung von Gehirn, Myelon, Muskeln, Sehnen, Bandscheiben, Gelenken mit ihren Band- und Knorpelstrukturen sowie dem Becken und den Oberbauchorganen (Hünerbein 2011).

Die MR-Bildgebung gilt bei einer Vielzahl von radiologischen Fragestellungen als diagnostischer Goldstandard.

\subsubsection{Artefakte}

Der Prozess der Signalerzeugung und Bildberechnung kann durch zahlreiche Faktoren gestört werden, was sich in der MRT-Aufnahme als Artefakt darstellt (Hünerbein 2011). Generell lassen sich Artefakte in drei Kategorien einteilen:

Durch Patienten verursachte Artefakte (Hünerbein 2011, Nowarra und Reiter 2014) Diese Artefakte können durch Bewegung des Patienten oder im Patienten, aber auch durch den Verlauf von Strukturen im Patienten entstehen. Im Einzelnen lässt sich hier unterscheiden:

- Bewegungsartefakte: bedingt durch Bewegungen des Patienten

- Fluss- oder Pulsationsartefakte: bedingt durch große Blutgefäße 
- Magic-Angle-Artefakt: bedingt durch Sehnen, welche in einem Winkel von $55^{\circ}$ zum Hauptmagnetfeld verlaufen

- Suszeptibilitätsartefakte: bedingt durch lokale Magnetfeldinhomogenitäten

Durch die Messmethode verursachte Artefakte (Hünerbein 2011, Nowarra und Reiter 2014)

Diese Artefakte können durch Gradientenverzerrungen, Einfaltungen, chemische Verschiebungen und Oszillation entstehen. Folgende Artefakte lassen sich hier unterscheiden:

- Einfaltungsartefakte: entstehen dort, wo das zu untersuchende Objekt größer ist als das field of view

- Chemische Verschiebungen: entstehen an fett- und wasserhaltigen Grenzstrukturen

- Oszillationsartefakte: auch bekannt als "Gibbs-Phänomen" (Krupa und Bekiesinska-Figatowska 2015), bedingt durch Signalschwingungen in der Nähe von scharfen, kontrastreichen Gewebegrenzen

Durch das System verursachte Artefakte (Nowarra und Reiter 2014)

Diese Artefakte können eine Vielzahl verschiedener Usachen haben. Neben einer defekten Spule, kann der Ursprung auch von Störsignalen im Raum (z.B defekte Glühbirne) herrühren. Außerdem können Entladungsvorgänge von Lagerungshilfen der Grund für eventuelle Störsignale sein. Das Risiko für Letzteres, lässt sich durch eine Luftfeuchtigkeit von über $50 \%$ minimieren. 


\section{Zielstellung der Arbeit}

Der Bulbus olfactorius nimmt als erster synaptischer Umschaltpunkt in der Verarbeitung der olfaktorischen Information, eine zentrale Rolle im Verlauf der Riechbahn ein. Mehrfach konnten Studien eine Korrelation zwischen dem Volumen des Bulbus olfactorius und der Riechfunktion aufzeigen (Buschhüter et al. 2008, Hummel et al. 2011, Hang et al. 2015). Ebenso besteht ein Zusammenhang zwischen einer olfaktorischen Beeinträchtigung und dem Auftreten neurodegenerativer Erkrankungen wie z.B. Morbus Alzheimer (Mesholam et al. 1998, Peters et al. 2003) oder Morbus Parkinson (Ansari und Johnson 1975, Doty 2012). Eine solche Beeinträchtigung der Riechfunktion gilt als eines der ersten Anzeichen für das Auftreten der genannten Krankheitsbilder und ist oftmals Jahre vor weiteren Krankheitssymptomen nachweisbar (Hüttenbrink et al. 2013). Sowohl Morbus Alzheimer als auch Morbus Parkinson gehen unter anderem mit einer Atrophie des Bulbus olfactorius einher (Thomann et al. 2009, Brodoehl et al. 2012). Die magnetresonanztomographische Bestimmung des BO-Volumens könnte daher als einfacher Marker zur Verlaufsobjektivierung, Erkennung und Diagnosesicherung entsprechender Krankheitsbilder beitragen.

Ziel der Studie war die Entwicklung und Erprobung eines Verfahrens zur vollautomatisierten Volumenbestimmung des Bulbus olfactorius aus MRTDatensätzen. 


\section{Probanden und Methodik}

\subsection{Probandenkollektiv}

In die Studie wurden ingesamt 40 unterschiedliche MRT-Datensätze eingeschlossen. Davon wurden 20 Datensätze neu erhoben und 20 Datensätze aus einem bestehenden Datenpool herangezogen.

\subsubsection{Neue Datensätze}

Die Aufnahmen der 20 neuen MRT-Datensätze erfolgte an 10 Probanden im Alter von 21 bis 37 Jahren (4 Frauen, 6 Männer, mittleres Alter: 25 Jahre). Keiner der Studienteilnehmer berichtete über bisherige Riechstörungen. Vor Beginn der Messungen erfolgte eine mündliche Aufklärung zu Studienablauf und -zielen.

Es wurden die üblichen Ausschlusskriterien für die Durchführung der Magnetresonanztomographie beachtet.

\begin{tabular}{c|c|c} 
Proband & Geschlecht & Alter \\
\hline Proband 1 & m & 22 Jahre \\
\hline Proband 2 & w & 24 Jahre \\
\hline Proband 3 & m & 23 Jahre \\
\hline Proband 4 & w & 22 Jahre \\
\hline Proband 5 & w & 24 Jahre \\
\hline Proband 6 & m & 24 Jahre \\
\hline Proband 7 & w Jahre \\
\hline Proband 8 & m & 25 Jahre \\
\hline Proband 9 & m & 37 Jahre \\
\hline Proband 10 & $\mathrm{m}$ & 29 Jahre
\end{tabular}

Tab. 2: Probandenkollektiv der neuen Datensätze 


\subsubsection{Bestehende Datensätze}

Es wurden zusätzlich 20 MRT-Datensätze aus einem bestehenden Datenpool in die Studie einbezogen. Das Probandenkollektiv bestand aus 12 Frauen und 8 Männern im Alter von 20 bis 28 Jahren (mittleres Alter: 25 Jahre).

\begin{tabular}{|c|c|c|}
\hline Proband & Geschlecht & Alter \\
\hline Proband 1 & w & 24 Jahre \\
\hline Proband 2 & w & 24 Jahre \\
\hline Proband 3 & $w$ & 24 Jahre \\
\hline Proband 4 & $\mathrm{~m}$ & 25 Jahre \\
\hline Proband 5 & $\mathrm{~m}$ & 27 Jahre \\
\hline Proband 6 & $\mathrm{~m}$ & 27 Jahre \\
\hline Proband 7 & $\mathrm{~m}$ & 27 Jahre \\
\hline Proband 8 & $\mathrm{~m}$ & 27 Jahre \\
\hline Proband 9 & w & 23 Jahre \\
\hline Proband 10 & w & 23 Jahre \\
\hline Proband 11 & w & 25 Jahre \\
\hline Proband 12 & w & 28 Jahre \\
\hline Proband 13 & w & 24 Jahre \\
\hline Proband 14 & $w$ & 24 Jahre \\
\hline Proband 15 & $m$ & 28 Jahre \\
\hline Proband 16 & $m$ & 28 Jahre \\
\hline Proband 17 & $\mathrm{~m}$ & 25 Jahre \\
\hline Proband 18 & $w$ & 20 Jahre \\
\hline Proband 19 & w & 23 Jahre \\
\hline Proband 20 & w & 23 Jahre \\
\hline
\end{tabular}

Tab. 3: Probandenkollektiv der bestehenden Datensätze 


\subsection{Magnetresonanztomographie (MRT)}

Um das Risiko für Gesundheitsschäden durch die MR-Untersuchung zu minimieren, erfolgte vor jeder Untersuchung eine ausführliche Patientenaufklärung durch einen Radiologen.

\subsubsection{Untersuchungssequenzen - Neue Datensätze}

Die MR-Untersuchungen zur Erhebung neuer MRT-Datensätze wurde am Universitätsklinikum Jena an einem 3 Tesla MR-Tomograph (MAGNETOM Prisma fit, Siemens Healthcare $\mathrm{GmbH}$, Erlangen, Deutschland) unter Verwendung einer 64Kanal-Kopfspule vorgenommen.

Im ersten Schritt wurde eine Planungssequenz in allen drei Raumebenen erhoben. Unter Orientierung an der anterioren und posterioren Kommissur in AC/PC Winkelung wurde das zu erfassende Zielvolumen registriert.

Im weiteren Vorgehen erfolgte die Erhebung der MR-Aufnahmen eines jeden Studienteilnehmers. Es wurde zur optimalen Darstellung des Bulbus olfactorius eine Constructive Interference Steady State (CISS) MR-Sequenz wie auch eine T2w TurboSpin-Echo 3D (TSE) MR-Sequenz gewählt (Burmeister et al. 2011b, Tsutsumi et al. 2017).

Alle Messungen erfolgten am selben Scanner. In der folgenden Tabelle sind die Messparameter im Einzelnen aufgeführt.

\begin{tabular}{c|c|c|c|c|c|c} 
& $\begin{array}{c}\text { Anzahl der } \\
\text { Schichten }\end{array}$ & Voxelgröße [mm] & Bildmatrix [mm] & Flip angle & TR [ms] & TE [ms] \\
\hline CISS & 52 & $0.4 \times 0.4 \times 0.4$ & $384 \times 512$ & 50 & 12.52 & 6.26 \\
\hline T2w TSE & 56 & $0.5 \times 0.5 \times 0.5$ & $384 \times 384$ & 120 & 1000 & 134
\end{tabular}

Tab. 4: Messparameter zur Erhebung neuer MRT-Datensätze

\subsubsection{Untersuchungssequenzen - Bestehende Datensätze}

Die MR-Untersuchungen der bestehenden MRT-Datensätze erfolgten am Universitätsklinikum Jena an einem 3 Tesla MR-Tomograph (MAGNETOM Trio, Siemens Healthcare $\mathrm{GmbH}$, Erlangen, Deutschland) unter Verwendung einer 64- 
Kanal-Kopfspule. Die Darstellung des Bulbus olfactorius erfolgte in einer Constructive Interference Steady State (CISS) MR-Sequenz.

Alle Messungen erfolgten am selben Scanner. In der folgenden Tabelle sind die Messparameter im Einzelnen aufgeführt.

\begin{tabular}{c|c|c|c|c|c|c} 
& $\begin{array}{c}\text { Anzahl der } \\
\text { Schichten }\end{array}$ & Voxelgröße [mm] & Bildmatrix [mm] & Flip angle & TR [ms] & TE [ms] \\
\hline CISS & 52 & $0.4 \times 0.4 \times 0.4$ & $384 \times 512$ & 50 & 12.18 & 6.09
\end{tabular}

Tab. 5: Messparameter der bestehenden MRT-Datensätze

\subsection{Datenauswertung und Software}

\subsubsection{MRIcron}

Die Aufarbeitung der einzelnen MR-Aufnahmen erfolgte mittels des plattformübergreifenden NIfTI Format Bildbetrachtungsprogramms "MRIcron" der University of South Carolina. Es handelt es sich um ein Freeware-Programm zur Markierung von Strukturen und Generierung von Volumen-Renderings auf Grundlage von MR-Aufnahmen.

Download URL: https://www.nitrc.org/projects/mricron

Die Segmentierung der jeweiligen Strukturen in den einzelnen Schichten erfolgte auf einem 13 Zoll MacBook Air mit dem Betriebssystem OS X El Capitan 10.11. Dabei wurden die Aufnahmen grauskaliert in coronarer Ansicht dargestellt. Helligkeit, Kontrast und Vergrößerung wurden nach subjektiven Empfinden bestmöglich angepasst. Die markierten Strukturen wurden anschließend als VOI-Datei abgespeichert. 


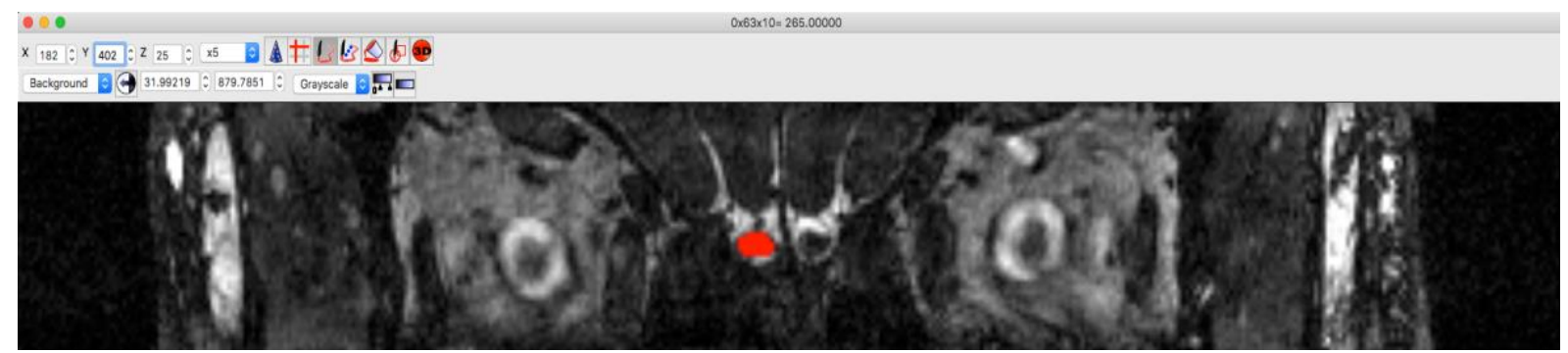

Abb. 8: Die Abbildung zeigt die CISS MR-Aufnahme von Proband Nr. 1 in coronarer Ansicht, dargestellt in MRIcron. Rot eingefärbt ist der Bulbus olfactorius rechts in radiologischer Konvention.

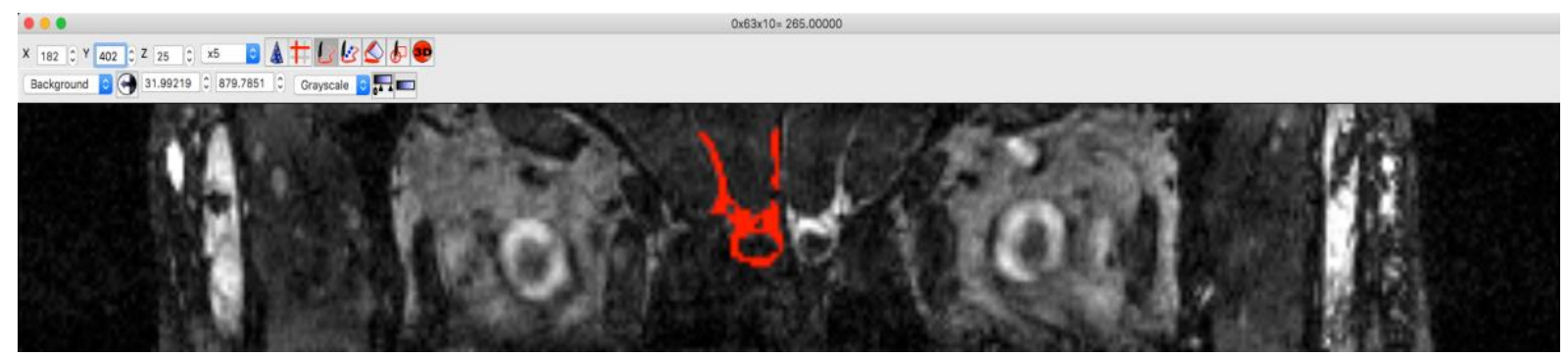

Abb. 9: Die Abbildung zeigt die CISS MR-Aufnahme von Proband Nr. 1 in coronarer Ansicht, dargestellt in MRIcron. Rot eingefärbt ist der Liquor cerebrospinalis rechts (Bereich der ROI) in radiologischer Konvention.

\subsubsection{Segmentierung}

Für die 20 neu erhobenen MRT-Datensätzen wurden folgende Strukturen unter Verwendung des Bildbetrachtungsprogramms "MRIcron" manuell segmentiert:

- Bulbus olfactorius links

- Bulbus olfactorius rechts

- Tractus olfactorius links

- Tractus olfactorius rechts

- Liquor cerebrospinalis links (jeweils nur die ROI)

- Liquor cerebrospinalis rechts (jeweils nur die ROI)

Bei der Region of Interest (ROI) handelt es sich um einen Bereich, welcher von besonderem Interesse ist. Im Fall der vorliegenden Studie war nur der, den Bulbus olfactorius umgebende, Liquor cerebrospinalis von Interesse. 
Die Segmentierung der o.g. Klassen erfolgte für die CISS- sowie die T2w TSE 3D MRAufnahmen eines jeden Probanden. Da die CISS MR-Aufnahme des Probanden 9 am ehesten artefaktbedingt keine ausreichende Segmentierung des Liquor cerebrospinalis (jeweils nur die ROI betreffend) zuließ, erfolgte diese nicht.

Die Segmentierung des BO ab distal wurde mit Beginn der Schicht, ab welcher dieser erstmals abzugrenzen war, vorgenommen. Proximal wurde die Begrenzung des $\mathrm{BO}$ anhand der sprunghaften Änderung des Durchmessers mit Beginn des distalen Tractus olfactorius definiert (Gudziol et al. 2009).

Für die 20 bestehenden MRT-Datensätze wurden folgende Strukturen unter Verwendung des Bildbetrachtungsprogramms "MRIcron" manuell segmentiert:

- Liquor cerebrospinalis links (jeweils nur die ROI)

- Liquor cerebrospinalis rechts (jeweils nur die ROI)

Die Segmentierung des linken und rechten Bulbus olfactorius war in dem bestehenden Datenpool bereits vorhanden und wurde nicht erneut durchgeführt.

\subsubsection{Algorithmus zur automatisierten Volumetrie}

Der Grundgedanke, des zur automatisierten MR-Volumetrie des Bulbus olfactorius verwendeten Algorithmus, beruht auf der Arbeit "Semantic Segmentation with Millions of Features: Integrating Multiple Cues in a Combined Random Forest Approach“ (Fröhlich et al. 2013). In dieser wurde anhand von 2D-Bildern ein semantischer Segementierungsansatz mit dem Namen Iterative Context Forests (ICF) entwickelt. Der Vorgang der semantischen Segmentierung basiert dabei auf dem massiven Einsatz von zufälligen Entscheidungswäldern und der Berechnung mehrerer grundlegender- sowie höherrangiger Kontextmerkmale, den sog. Features. Hierbei handelt es sich um Klassen wie beispielsweise Farbe oder geometrischer Kontext, welche durch den Algorithmus zufällig festgelegt werden. Definierte Features werden anschließend auf jeden einzelnen Bild-Pixel angewandt und versucht, diesen entsprechend zu klassifizieren. Um die fortlaufende Erkennung und Zuordnung einzelner Pixel zu bestehenden Featureklassen sowie die weitere Differenzierung neuer Features zu gewährleisten, bedienten sich Fröhlich et al einem Konzept, 
welches unter dem Namen „auto-context" bekannt ist (Tu und Bai 2010). Dabei werden neue Features auf Grundlage früherer Klassifizierungsergebnisse berechnet und versucht diese weiter zu differenzieren. Abbildung 10 gibt einen Überblick über diesen Vorgang.

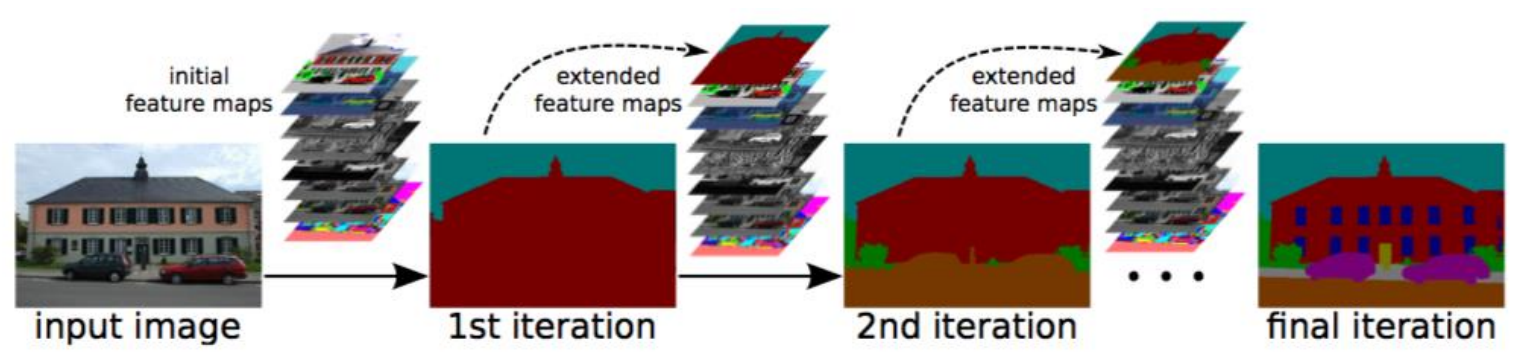

Abb. 10: Grundlegende Idee der Arbeit von Fröhlich et al. Features werden inkrementell zu den verfügbaren Funktionen hinzugefügt und aktualisiert, um das Ergebnis der semantischen Segmentierung zu verfeinern (Fröhlich et al. 2013).

Sickert et al. griffen die Methode der semantischen Segmentierung auf und erweiterten sie in der Arbeit "Semantic Volume Segmentation with Iterative Context Integration for Bio-medical Image Stacks“ (Sickert et al. 2016). Sie findet so auch Anwendung bei der automatisierten Volumetrie des Bulbus olfactorius aus MRT-Datensätzen. Die Iterative Context Forests (ICF) wurden dabei so angepasst, dass die bestehenden Koordinatenebenen $x$ und y um die Tiefenebene $z$ ergänzt wurden. Dies ermöglicht den ursprünglich zur Segmentierung von 2D-Bilddaten entwickelten Algorithmus nun auf 3D-Bilddaten anzuwenden. Der ursprüngliche Name ICF wurde zu ICF3D geändert.

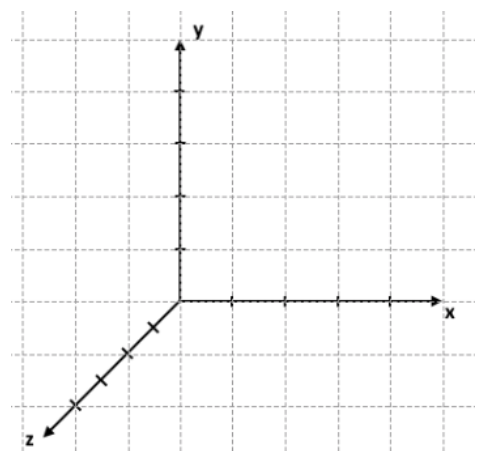

Abb. 11: Abbildung der von Sickert et al. verwendeten Koordinatenebenen. Dabei steht $\mathrm{x}$ für die Breite, y für die Höhe und $z$ für die Tiefe. 
Anhand der manuell durchgeführten Segmentierungen der in Kapitel 5.3.2 genannten Klassen berechnete der Algorithmus eine gewisse Anzahl zufälliger Features zur Differenzierung des Bulbus olfactorius von dessen Umgebung. Mittels berechneter Features wurden die ICF anschließend trainiert. Abbildung 12 dient der weiteren Verdeutlichung dieses Vorgangs. Dabei stellt $t$ das erste, anhand eines bestimmten Features festgelegte, Differenzierungslevel dar. Diese Zuordnung wird im Folgenden erneut auf den Bilddatensatz übertragen und eine mögliche Klasseneinteilung der einzelnen Voxel vorgenommen. Auf Grundlage der gegenwärtigen Zuordnung einzelner Voxel zum Bulbus olfactorius oder dessen Umgebung erfolgt nun eine erneute Differenzierung anhand eines weiteren zufälligen Features. Dies entspricht dem Level $\mathrm{t}+1$. Das Vorgehen wird gemäß dem oben genannten Konzept „autocontext" fortgeführt und dient der Erstellung eines Feature-Pools.

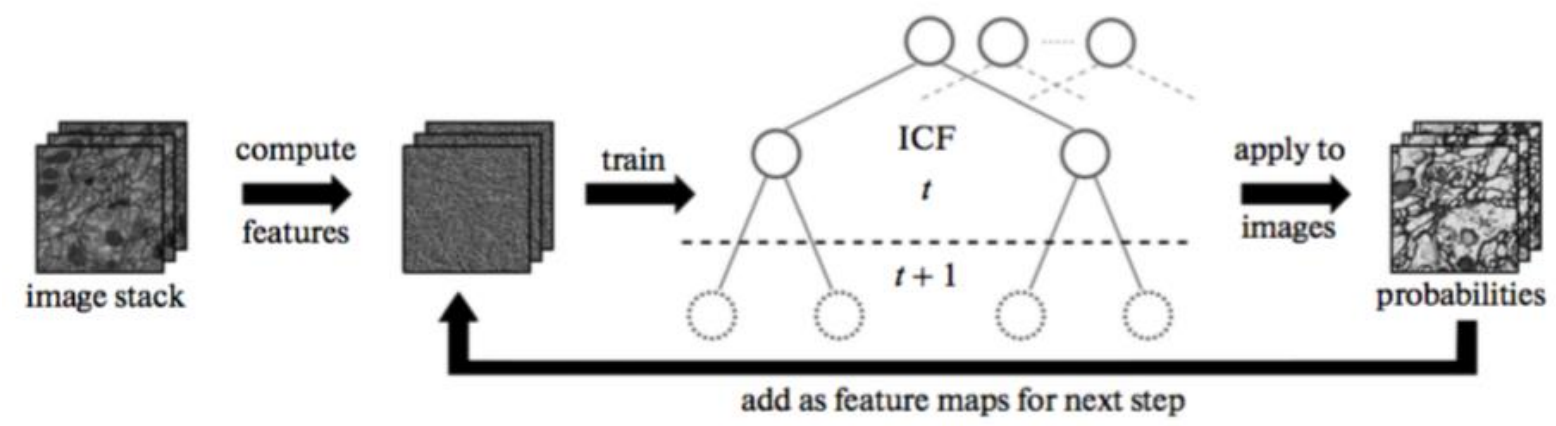

Abb. 12: Grundstruktur der angewandten Methodik (Sickert et al. 2016)

Bei der Erstellung dieses Feature-Pools wird jeder einzelne Bildpunkt sowie dessen Umgebungsstruktur gesondert betrachtet. Da mit der Größe der Umgebungsstruktur auch die Größe des Feature-Pools exponentiell ansteigt, ist es nicht möglich alle möglichen Merkmale zu berechnen. Dieses Problem löst man, indem nur eine bestimmte Anzahl von Features in einer festgelegten 3D-Umgebung der Länge d des betreffenden Voxels berechnet wird. 


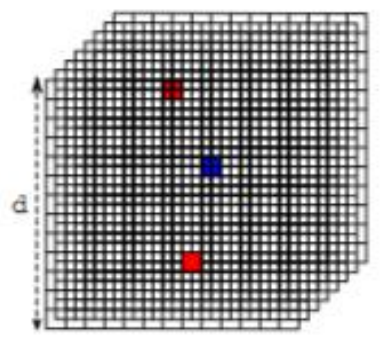

(a)

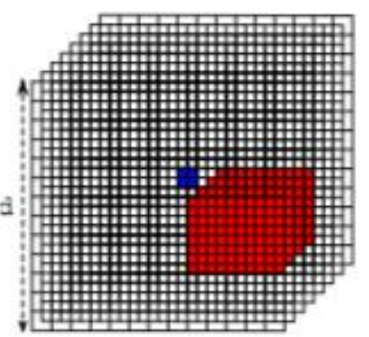

(b)

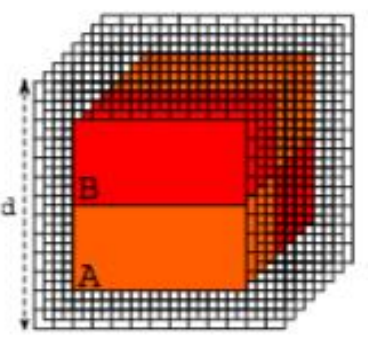

(c)

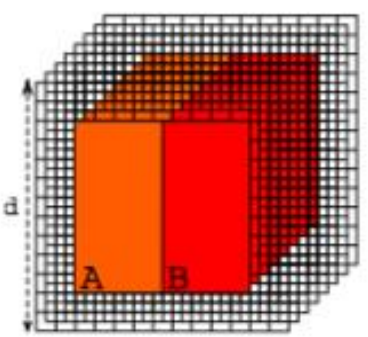

(d)

Abb. 13: Prozess der Merkmalsextraktion für eine 3D-Nachbarschaft der Seitenlänge d um einen zentrierten Voxel (blau): (a) Voxel-Paare, (b) kleiner Quader beliebiger Größe, (c und d) verschiedene Arten von 3D-Haar-like features wobei das Feature die Differenz der Summen einzelner Voxelintensitäten von dunkleren und helleren Regionen ist (Sickert et al. 2016).

Nach ausreichendem Training des Algorithmus anhand festgelegter Features, fand das Verfahren Anwendung bei einem bis dahin unbekannten MRT-Datensatz. Der gesamte Prozess hinsichtlich Selbsttraining und Klasseneinteilung des Algorithmus verläuft selbständig und automatisiert.

\subsubsection{Einstellungen des Algorithmus}

Die in Kapitel 5.3.3 genannte 3D-Umgebung eines Voxels der Seitenlänge $d$ wurde bei der automatisierten MR-Volumetrie des BO je nach Aufnahmesequenz unterschiedlich festgelegt. Die Länge d wurde für die jeweiligen Sequenzen wie folgt definiert:

- CISS neue Aufnahmen: $d=20$ [Pixel]

- T2 neue Aufnahmen: $d=10$ [Pixel]

- CISS bestehende Aufnahmen: $d=50$ [Pixel]

Zur automatisierten Messung des BO-Volumens aller 40 MRT-Datensätze wurde eine einheitliche ROI von $100 \times 100$ [Pixel] festgelegt. 


\section{Ergebnisse}

Es werden die Ergebnisse der 20 neu erhobenen MRT-Datensätze und der 20 bestehenden MRT-Datensätze aufgeführt.

Der Erkennungsalgorithmus fand jeweils für die neuen CISS-Datensätze, die neuen T2-Datensätze und die bestehenden CISS-Datensätze mittels einer Leave-One-Out Kreuzvalidierung statt.

Im Folgenden wird zusätzlich die prozentuale Abweichung der Ergebnisse der automatisierten Messung von der manuellen Messung genannt, welche sich aus dem Verhältnis der automatisierten Messung zu der manuellen Messung berechnet.

\subsection{Ergebnisse der CISS Aufnahmen}

\begin{tabular}{c|c|c|c|c|c|c}
\multirow{2}{*}{ Proband } & \multicolumn{2}{|c|}{$\begin{array}{c}\text { BO-Volumen [mm } \\
\text { manuelle Messung }\end{array}$} & \multicolumn{2}{c|}{$\begin{array}{c}\left.\text { Bo-Volumen [mm }{ }^{3}\right] \\
\text { automatisierte Messung }\end{array}$} & \multicolumn{2}{c}{ Abweichung } \\
\cline { 2 - 7 } & Bulbus L & Bulbus R & Bulbus L & Bulbus R & Bulbus L & Bulbus R \\
\hline Proband 1 & 65,90 & 66,23 & 57,56 & 29,86 & $12,66 \%$ & $54,91 \%$ \\
\hline Proband 2 & 49,42 & 71,54 & 21,05 & 33,42 & $57,41 \%$ & $53,28 \%$ \\
\hline Proband 3 & 51,10 & 47,14 & 47,00 & 62,96 & $8,02 \%$ & $33,56 \%$ \\
\hline Proband 4 & 54,06 & 54,20 & 106,51 & 69,80 & $97,02 \%$ & $28,78 \%$ \\
\hline Proband 5 & 55,14 & 50,09 & 22,26 & 49,22 & $59,63 \%$ & $1,74 \%$ \\
\hline Proband 6 & 82,71 & 74,30 & 57,42 & 46,53 & $30,58 \%$ & $37,38 \%$ \\
\hline Proband 7 & 42,90 & 51,78 & 78,60 & 89,56 & $83,22 \%$ & $72,96 \%$ \\
\hline Proband 8 & 45,59 & 44,48 & 58,30 & 42,77 & $27,88 \%$ & $3,84 \%$ \\
\hline Proband 9 & 32,34 & 29,25 & 72,82 & 71,07 & $125,17 \%$ & $142,97 \%$ \\
\hline Proband 10 & 26,36 & 34,97 & 97,03 & 91,85 & $268,10 \%$ & $162,65 \%$ \\
\hline Durchschnitt & 50,55 & 52,40 & 61,86 & 58,70 & $22,36 \%$ & $12,03 \%$
\end{tabular}

Tab. 6: Gemessene Volumina des Bulbus olfactorius in $\mathrm{mm}^{3}$. ROI 100x100 [Pixel]. Seitenlänge $d=20$ [Pixel]. $L=$ links, $R=$ rechts. Constructive Interference in Steady State MR-Sequenz. 

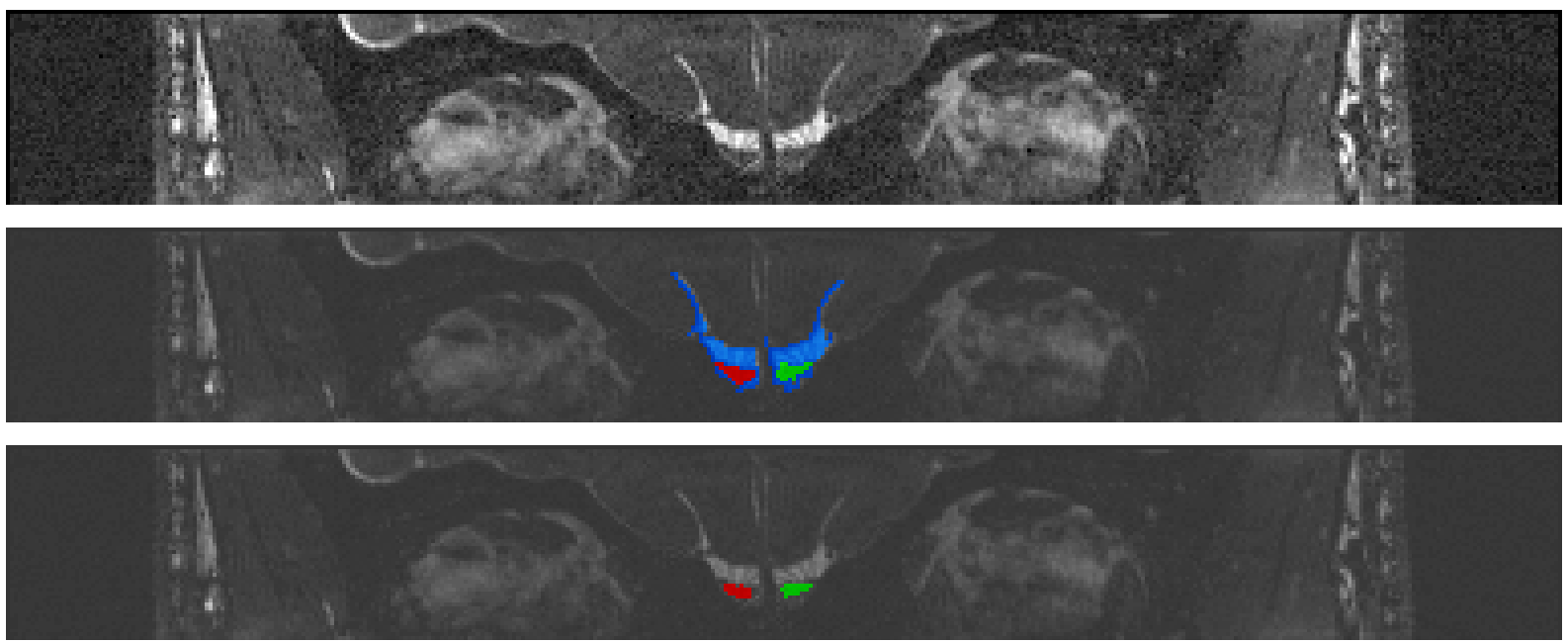

Abb. 14: Originalaufnahme (oben) sowie farblich markiertes Overlay der manuell (Mitte) und vollautomatisiert (unten) segmentierten Strukturen, in vergleichender Darstellung. Proband Nr. 3, CISS MRT-Aufnahme der neuen Datensätze, koronare Ansicht, radiologische Konvention. Rot - BO rechts, grün - BO links, blau - Liquor cerebrospinalis.

\subsection{Ergebnisse der T2 Aufnahmen}

\begin{tabular}{c|c|c|c|c|c|c}
\multirow{2}{*}{ Proband } & \multicolumn{2}{|c|}{$\begin{array}{c}\text { BO-Volumen [mm } \\
\text { manuelle Messung }\end{array}$} & \multicolumn{2}{c|}{$\begin{array}{c}\text { BO-Volumen [mm } \\
\text { automatisierte Messung }\end{array}$} & \multicolumn{2}{c}{ Abweichung } \\
\cline { 2 - 6 } & Bulbus L & Bulbus R & Bulbus L & Bulbus R & Bulbus L & Bulbus R \\
\hline Proband 1 & 39,75 & 36,37 & 113,16 & 70,30 & $184,68 \%$ & $93,29 \%$ \\
\hline Proband 2 & 54,89 & 61,25 & 0,00 & 23,66 & $100,00 \%$ & $61,37 \%$ \\
\hline Proband 3 & 38,26 & 30,29 & 45,97 & 46,91 & $20,15 \%$ & $54,87 \%$ \\
\hline Proband 4 & 32,18 & 35,15 & 122,22 & 36,10 & $279,80 \%$ & $2,70 \%$ \\
\hline Proband 5 & 32,18 & 31,50 & 85,72 & 71,79 & $166,38 \%$ & $127,90 \%$ \\
\hline Proband 6 & 44,48 & 37,72 & 62,33 & 30,69 & $40,13 \%$ & $18,64 \%$ \\
\hline Proband 7 & 25,69 & 36,23 & 69,90 & 54,62 & $172,09 \%$ & $50,76 \%$ \\
\hline Proband 8 & 26,63 & 30,56 & 75,17 & 81,66 & $182,28 \%$ & $167,21 \%$ \\
\hline Proband 9 & 35,56 & 31,23 & 82,34 & 95,45 & $131,55 \%$ & $205,64 \%$ \\
\hline Proband 10 & 45,43 & 33,39 & 86,12 & 57,73 & $89,57 \%$ & $72,90 \%$ \\
\hline Durchschnitt & 37,51 & 36,37 & 74,29 & 56,89 & $98,09 \%$ & $56,43 \%$
\end{tabular}

Tab. 7: Gemessene Volumina des Bulbus olfactorius in $\mathrm{mm}^{3}$. ROI 100x100 [Pixel]. Seitenlänge d=10 [Pixel]. $L=$ links, $R=$ rechts. T2 MR-Sequenz. 

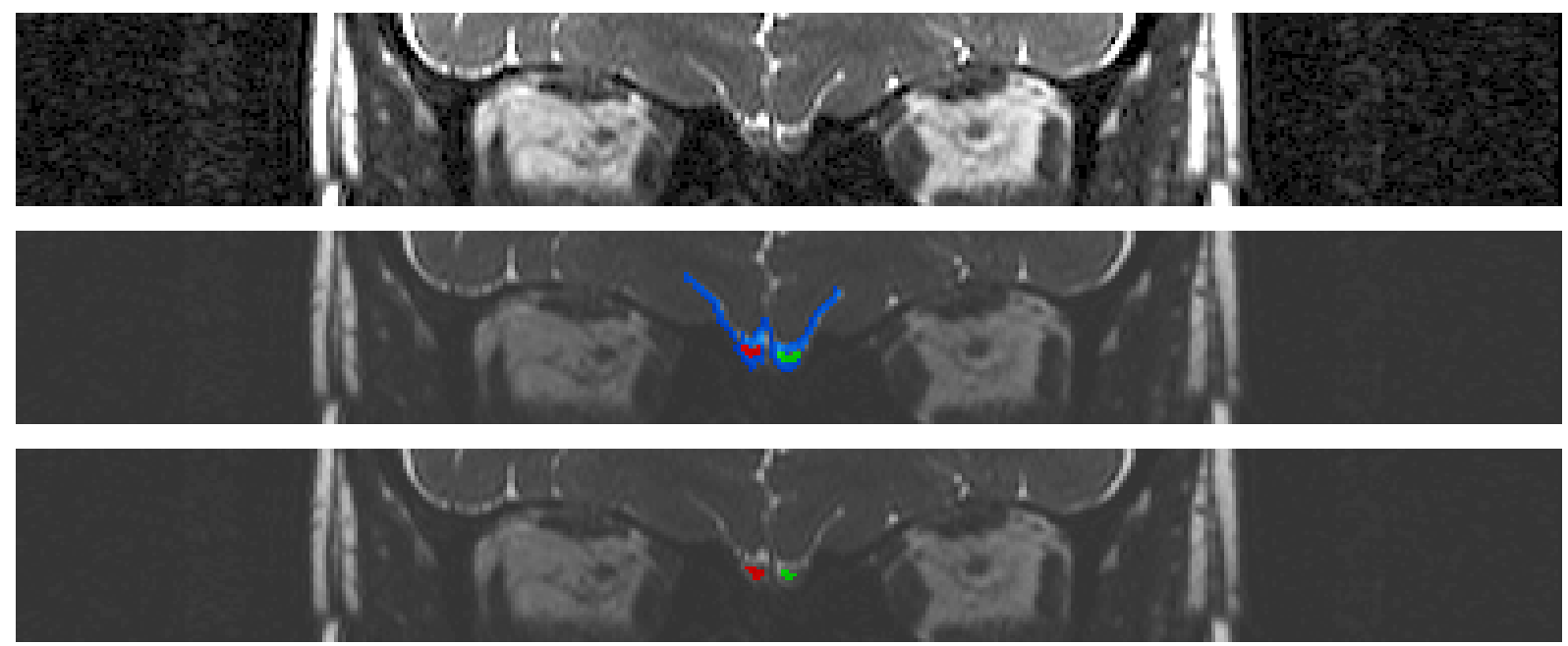

Abb. 15: Originalaufnahme (oben) sowie farblich markiertes Overlay der manuell (Mitte) und vollautomatisiert (unten) segmentierten Strukturen, in vergleichender Darstellung. Proband Nr. 5, T2 MRT-Aufnahme der neuen Datensätze, koronare Ansicht, radiologische Konvention. Rot - BO rechts, grün - BO links, blau - Liquor cerebrospinalis. 


\subsection{Ergebnisse der bestehenden Datensätze}

\begin{tabular}{|c|c|c|c|c|c|c|}
\hline \multirow{2}{*}{ Proband } & \multicolumn{2}{|c|}{$\begin{array}{l}\text { BO-Volumen }\left[\mathrm{mm}^{3}\right] \\
\text { manuelle Messung }\end{array}$} & \multicolumn{2}{|c|}{$\begin{array}{c}\left.\text { BO-Volumen [mm }{ }^{3}\right] \\
\text { automatisierte Messung }\end{array}$} & \multicolumn{2}{|c|}{ Abweichung } \\
\hline & Bulbus L & Bulbus R & Bulbus L & Bulbus R & Bulbus L & Bulbus $\mathbf{R}$ \\
\hline Proband 1 & 69,46 & 75,65 & 99,92 & 138,58 & $43,85 \%$ & $83,19 \%$ \\
\hline Proband 2 & 56,55 & 63,34 & 148,20 & 197,35 & $162,07 \%$ & $211,57 \%$ \\
\hline Proband 3 & 62,06 & 57,09 & 109,47 & 77,26 & $76,39 \%$ & $35,33 \%$ \\
\hline Proband 4 & 91,25 & 88,35 & 151,42 & 188,00 & $65,94 \%$ & $112,79 \%$ \\
\hline Proband 5 & 55,54 & 57,15 & 177,18 & 200,17 & $219,01 \%$ & $250,25 \%$ \\
\hline Proband 6 & 56,89 & 60,79 & 130,51 & 150,62 & $129,41 \%$ & $147,77 \%$ \\
\hline Proband 7 & 68,45 & 80,42 & 169,98 & 217,39 & $148,33 \%$ & $170,32 \%$ \\
\hline Proband 8 & 66,30 & 77,93 & 167,83 & 215,84 & $153,14 \%$ & $176,97 \%$ \\
\hline Proband 9 & 58,70 & 55,94 & 129,77 & 200,91 & $121,07 \%$ & $259,15 \%$ \\
\hline Proband 10 & 55,20 & 51,84 & 115,79 & 210,39 & $109,76 \%$ & $305,84 \%$ \\
\hline Proband 11 & 59,58 & 63,21 & 171,19 & 193,45 & $187,33 \%$ & $206,04 \%$ \\
\hline Proband 12 & 53,19 & 54,13 & 121,50 & 198,83 & $128,43 \%$ & $267,32 \%$ \\
\hline Proband 13 & 67,37 & 60,65 & 123,72 & 159,96 & $83,64 \%$ & $163,74 \%$ \\
\hline Proband 14 & 66,03 & 68,25 & 125,20 & 142,62 & $89,61 \%$ & $108,97 \%$ \\
\hline Proband 15 & 72,08 & 71,07 & 155,93 & 182,36 & $116,33 \%$ & $156,59 \%$ \\
\hline Proband 16 & 72,89 & 73,56 & 184,31 & 175,97 & $152,86 \%$ & $139,22 \%$ \\
\hline Proband 17 & 66,16 & 77,66 & 117,00 & 168,17 & $76,84 \%$ & $116,55 \%$ \\
\hline Proband 18 & 49,42 & 56,75 & 26,49 & 50,23 & $46,40 \%$ & $11,49 \%$ \\
\hline Proband 19 & 71,95 & 68,18 & 177,25 & 140,73 & $146,35 \%$ & $106,41 \%$ \\
\hline Proband 20 & 73,90 & 71,01 & 121,47 & 184,10 & $64,37 \%$ & $159,26 \%$ \\
\hline Durchschnitt & 64,65 & 66,65 & 136,21 & 169,65 & $110,69 \%$ & $154,54 \%$ \\
\hline
\end{tabular}

Tab. 8: Gemessene Volumina des Bulbus olfactorius in $\mathrm{mm}^{3}$. ROI 100x100 [Pixel]. Seitenlänge $d=50$ [Pixel]. $L=$ links, $R=$ rechts. Constructive Interference in Steady State MR-Sequenz. 

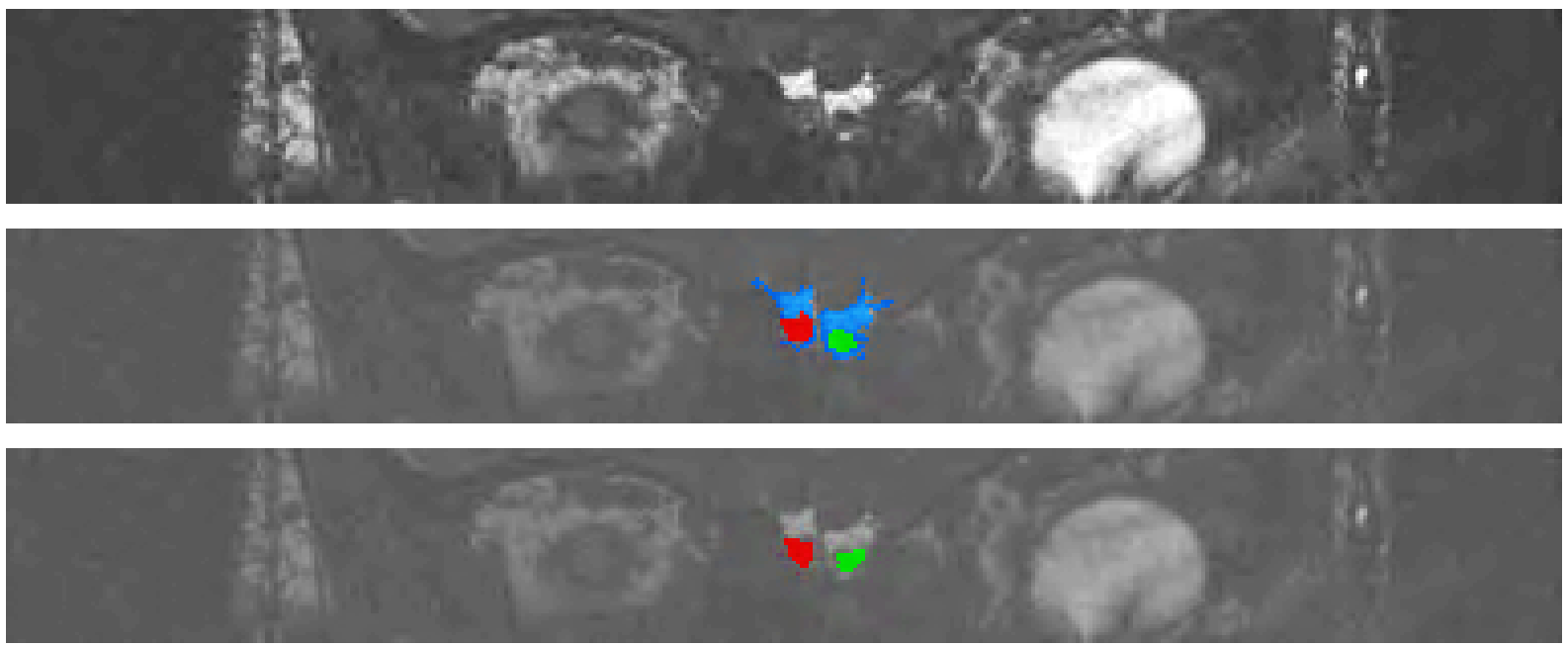

Abb. 16: Originalaufnahme (oben) sowie farblich markiertes Overlay der manuell (Mitte) und vollautomatisiert (unten) segmentierten Strukturen, in vergleichender Darstellung. Proband Nr. 3, CISS MRT-Aufnahme der bestehenden Datensätze, koronare Ansicht, radiologische Konvention. Rot - BO rechts, grün - BO links, blau - Liquor cerebrospinalis. 


\section{Diskussion}

\subsection{MR-Volumetrie}

Die Volumetrie aus MRT-Datensätzen ist eine beliebte Methode zur volumetrischen Untersuchung einer Vielzahl von Strukturen des menschlichen Körpers. Sie findet bereits seit mehreren Jahren sowohl in der klinischen Diagnostik (Mayr et al. 2002, Kang et al. 2010) als auch in der medizinischen Forschung (Yousem et al. 1996, Yousem et al. 1998, Buschhüter et al. 2008, Brabec et al. 2010, Hang et al. 2015) Anwendung. Bei den volumetrisch untersuchten Strukturen handelt es sich meist um Tumoren oder Organe des zentralen Nervensystems. Daher ist zu empfehlen, die Aufnahmen der MRT-Datensätze an einem Kernspintomographen mit einer Feldstärke von mindestens 1,5 Tesla vorzunehmen. Dies ermöglicht eine möglichst genaue Darstellung der abzubildenden Strukturen und senkt die Wahrscheinlichkeit falsche Volumenwerte zu erheben. Ebenso ist auf die Entstehung von Artefakten zu achten und nach Möglichkeit zu vermeiden. Artefakte sind als Folge einer Störung innerhalb der Signalerzeugung und Bildberechnung anzusehen und können dabei auf drei Arten entstehen: durch den Patienten, durch die Messmethode oder durch das System (Hünerbein 2011, Nowarra und Reiter 2014). Eine ausführlichere Einteilung sowie Erläuterung hinsichtlich Entstehungsmechanismen von Artefakten ist Kapitel 3.4.1 zu entnehmen. Kommt es während den MRT-Aufnahmen doch zur Artefaktentstehung kann daraus je nach Lokalisation und Ausmaß eine ungenaue Darstellung von Strukturgrenzen resultieren. Dies führt zur einer erschwerten Segmentierung v.a. kleiner Körperstrukturen und hat in den meisten Fällen die Erhebung falscher Volumenwerte zur Folge.

Um bestimmte Körperstrukturen nach Erhebung der MRT-Datensätze auf ihre volumetrischen Eigenschaften untersuchen zu können, müssen diese zunächst anatomisch von ihrer Umgebung abgegrenzt, d.h. segmentiert, werden. Generell stehen für die Segmentierung drei Ansätze zur Verfügung (Tittgemeyer und von Cramon 2004):

1. Manuelles Markieren durch einen Experten. Dabei handelt es sich um ein genaues, jedoch zeitaufwändiges Verfahren (Fiez et al. 2000). 
2. Automatische Segmentierung durch eine Bildverarbeitungsprozedur. Diese Möglichkeit besteht nur, sofern die zu segmentierende Struktur algorithmisch abgrenzbar ist (Tittgemeyer und von Cramon 2004).

3. Hochdimensionale Deformation auf ein vorsegmentiertes Gehirn. So lassen sich auch im Kernspintomographen nicht sichtbare Strukturen indirekt vermessen (Tittgemeyer und von Cramon 2004).

Nach Segmentierung der anatomischen Struktur wird mittels einer Gleichung - unter Berücksichtigung der Schichtdicke und der dazwischenliegenden Fläche - das Volumen errechnet (Brabec et al. 2010). Dabei gilt, je kleiner die dreidimensionale Bildeinheit (Voxel) gewählt wird, desto genauer die Darstellung der Struktur (Reith 2011) und desto exakter das errechnete Volumen. Der Ausdruck Voxel setzt sich aus den englischen Begriffen „volumetric“ und „pixel“ zusammen. Pixel bedeutet „Bildpunkt“ und somit ist ein Voxel als das dreidimensionale Äquivalent eines Pixels anzusehen. Neben der Voxelgröße ist auch die Schichtdicke der MR-Aufnahme so gering wie möglich zu wählen. Diese Einstellung dient dazu, das Auftreten von Partialvolumeneffekten nach Möglichkeit zu verhindern. Bei diesem Effekt handelt es sich um eine methodenbedingte Ungenauigkeit der Bilddarstellung, welche zu einer schlechten Abgrenzbarkeit einzelner Bilddetails führt (Laubenberger und Laubenberger 1999). In der Regel zeigt sich dies in einer schlechten Darstellung von Gewebegrenzflächen (Nitz et al. 2007). Grund hierfür ist die Rechteckgeometrie der Voxel. Aufgrund dieser Geometrie tragen oft nicht nur die interessierenden Objekte wie z.B. ein Rundherd zum Voxel bei, sondern entsprechend ihrem Volumenanteil auch die Umgebung. Der resultierende Wert des Voxels ist demgemäß etwas verfälscht und stellt die Summe der verschiedenen Schwächungswerte dar (Reith 2011). Dieses Phänomen ist besonders bei Aufnahmen mit großer Schichtdicke zu beobachten, da das Signal aus der z.B. pathologischen Region das Signal aus benachbartem gesundem Gewebe soweit überlagert, dass die Erkennbarkeit eingeschränkt ist (Nitz et al. 2007). Für den Fall der Bulbusvolumetrie sind möglichst kleine Werte hinsichtlich Voxelgröße und Schichtdicke zu wählen. 


\subsubsection{Bulbusvolumetrie}

Die MR-Volumetrie des Bulbus olfactorius findet bisher v.a. in der Forschung, nicht aber im klinischen Alltag, ihren Einsatz. Diese Tatsache ist damit zu begründen, dass ein zeitsparendes Verfahren zur BO-Volumetrie bisher noch nicht existiert. Alle in der Vergangenheit veröffentlichten Studien, welche das Volumen des BO untersuchten, unterlagen einer manuellen Struktursegmentierung. Diese Art der Segmentierung stellt zwar, wie in Kapitel 7.1 beschrieben, das genaueste Segmentierungsverfahren dar, ist jedoch sehr zeitaufwendig (Fiez et al. 2000). Zumeist lässt der klinische Alltag im Krankenhaus keine Zeit die routinemäßige volumetrische Untersuchung des Bulbus olfactorius in Krankheitsdiagnostik und -verlauf miteinzubeziehen. Dennoch konnten in den vergangenen Jahren zahlreiche Studien die klinische sowie diagnostische Wertigkeit des BO-Volumens darlegen. Im Folgenden ein kurzer Überblick über wichtige bisherige Studien zur Bulbusvolumetrie.

Bereits 1996 untersuchten Yousem et al. den Bulbus olfactorius volumetrisch und konnten bei sämtlichen Patienten mit kongenitaler Hyposomie oder Anosmie eine Aplasie bzw. Hypoplasie des Bulbus- und Tractus olfactorius nachweisen (Yousem et al. 1996). Selbige Arbeitsgruppe untersuchte zwei Jahre später unter anderem den Zusammenhang zwischen dem Volumen des Bulbus und Tractus olfactorius (TO) und dem Riechvermögen. Damals konnte allerdings keine Korrelation zwischen dem Riechvermögen und der Größe von BO sowie TO festgestellt werden (Yousem et al. 1998). Im Jahr 2005 veröffentlichten Mueller et al. eine Studie, welche bei Patienten mit postinfektiösem und posttraumatischem Riechdefizit ein geringeres Volumen des BO nachwies als bei Patienten ohne Parosmie (Mueller et al. 2005). Diese Befunde sowie die Befunde von Rombaux et al. deuteten stark auf eine Korrelation zwischen der Riechfunktion und dem BO-Volumen hin (Mueller et al. 2005, Rombaux et al. 2006). Doch erst Buschhüter et al. gelang es im Jahr 2008, an einem Kollektiv von 125 Probanden, einen signifikanten Zusammenhang zwischen der Riechfunktion und Volumen des Bulbus olfactorius nachzuweisen. Darüber hinaus wurde die Korrelation zwischen dem BO-Volumen und der Riechfunktion nicht durch das Alter der Probanden vermittelt. Im Durchschnitt zeigten sich die gemessenen BO-Volumina bei Männern (links: $70\left[\mathrm{~mm}^{3}\right]$.; rechts $69\left[\mathrm{~mm}^{3}\right]$ ) größer als bei Frauen (links: $64\left[\mathrm{~mm}^{3}\right]$; rechts: $\left.65\left[\mathrm{~mm}^{3}\right]\right)$, wohingegen die intraindividuelle Variation relativ gering war (Korrelation zwischen links- und rechtsseitigen BO-Volumina) (Buschhüter et al. 2008). 
Auf Grundlage dieser Befunde untersuchten Negoias et al. die Volumenänderung des BO unter dem Einfluss von Riechtraining. Es zeigte sich, dass nach 4 Monaten lateralisierten Riechtrainings, eine signifikante, bilaterale Volumenzunahme des BO zu verzeichnen war (Negoias et al. 2017). Eine Vielzahl weiterer Studien erforschten das BO-Volumen in Zusammenhang mit neurodegenerativen Erkrankungen. Hierbei sind vor allem die beiden Krankheitsbilder M. Alzheimer und M. Parkinson zu nennen. Beide Erkrankungen gehen in ihrem Verlauf, neben einer frühzeitigen Hyposmie, unter anderem mit einem Volumenverlust des BO einher. Dies konnten Thomann et al. für den M. Alzheimer (Thomann et al. 2009) und Wang et al. sowie Brodoehl et al. für den M. Parkinson (Wang et al. 2011, Brodoehl et al. 2012) aufzeigen. Die genaue Genese des Volumenverlustes des BO und ob die frühzeitige Hyposmie eventuell auf ein geringeres BO-Volumen zurückzuführen ist, ist bisher noch nicht ausreichend erforscht. Es existieren weitere Krankheitsbilder neurodegenerativer sowie psychiatrischer Genese, für welche in den vergangenen Jahren eine Volumenänderung des BO nachgewiesen werden konnte. Dabei handelt es sich um Depression (Negoias et al. 2010, Croy et al. 2013, Negoias et al. 2016), Schizophrenie (Turetsky et al. 2000, Nguyen et al. 2011), Temporallappenepilepsie (Hummel et al. 2013), Multiple Sklerose (Goektas et al. 2011) und den idiopathischen Normaldruckhydrocepahlus (Podlesek et al. 2012). Diese Volumenänderungen scheinen entweder durch einen direkten Einfluss auf den BO oder aber durch topdown Prozesse vermittelt zu werden (Negoias et al. 2017).

Für alle oben genannten Studien wurde eine manuelle Struktursegmentierung zur Volumetrie des BO aus MRT-Datensätzen durchgeführt. Um eine solche Volumetrie unter optimaler BO-Darstellung zu ermöglichen, untersuchten Burmeister et al., welche Aufnahmesequenzen an einem 3T MR-Tomographen hierfür am besten geeignet sind. Es zeigte sich, dass die Constructive Interference in Steady State (CISS) Sequenz aufgrund ihrer Genauigkeit die bestmögliche Aufnahmesequenz darstellt (Burmeister et al. 2011b). 


\subsection{Diskussion der Methodik}

Die Aufnahmen der 20 eigenen MRT-Datensätze erfolgten am Universitätsklinikum Jena an einem 3T MR-Tomographen (MAGNETOM Prisma fit, Siemens Healthcare $\mathrm{GmbH}$, Erlangen, Deutschland) unter Verwendung einer 64-Kanal Kopfspule. Die Aufnahmen der 20 bestehenden MRT-Datensätze wurden ebenfalls am Universitätsklinikum Jena an einem 3T MR-Tomographen (MAGNETOM Trio, Siemens Healthcare $\mathrm{GmbH}$, Erlangen, Deutschland) unter Verwendung einer 64Kanal Kopfspule vorgenommen. Der Homepage des MRT-Herstellers Siemens Healthcare $\mathrm{GmbH}$ (https://www.healthcare.siemens.de) ist zu entnehmen, dass ein Upgrade von MAGNETOM Trio auf MAGNETOM Prisma ${ }^{\text {fit }}$ unter anderem zu einer Erhöhung des Signal- zu Rausch-Verhältnisses (SNR) führt. Das SNR ist definiert als Wechselwirkung zwischen dem MR-Signal und der Stärke des Rauschens. Zur optimalen Bildauflösung ist daher ein möglichst hohes SNR wünschenswert (Reith 2011). Diese wichtige sowie weitere, zweitrangige, Verbesserungen brachte das Upgrade auf MAGNETOM Prisma fit mit sich und ermöglichte eine verbesserte Darstellung des BO bei den Aufnahmen der 20 neuen MRT-Datensätze. Weitere technische Details hinsichtlich des MRT-Upgrades sind der Homepage des Herstellers zu entnehmen. Die anfängliche Geräteauswahl orientierte sich an einer Studie von Burmeister et al., in welcher die hochauflösende Magnetresonanztomographie an einem 3T MR-Tomographen als geeignet zur BO-Volumetrie beschrieben wird (Burmeister et al. 2011a). Die gewählten Aufnahmesequenzen aller 40 MRTDatensätze orientierten sich ebenfalls an den Erkenntnissen selbiger Arbeitsgruppe. Sie zeigten, dass v.a. die CISS-Sequenz eine sehr gute Abbildung des BO ermöglicht und ebenso unerfahrenen Untersuchern die Möglichkeit einer genauen Struktursegmentierung bietet. Auch die T2w TSE 3D Sequenz wird in der Studie von Burmeister et al. beschrieben, zeigte in diesem Zusammenhang jedoch eine leicht verminderte Darstellungsgenauigkeit im Vergleich zur CISS-Sequenz (Burmeister et al. 2011b). Zur Überprüfung inwiefern sich diese Erkenntnisse auf das Verfahren der automatisierten MR-Volumetrie des BO auswirken bzw. zur Klärung der für das automatisierte Verfahren am besten geeigeneten Sequenz, wurden Aufnahmen in CISS- sowie T2w TSE 3D Sequenz angefertigt und in die vorliegende Studie eingeschlossen. 
Bei der Magnetresonanztomographie handelt es sich im Allgemeinen um ein leicht durch Artefakte beeinflussbares Verfahren. Dies zeigen in erster Linie die neuen CISS MR-Aufnahmen von Proband 9. Bei diesem war artefaktbedingt eine genaue Darstellung und Segmentierung des Liquor cerebrospinalis rechts und links (jeweils die ROI) nicht möglich. Die Segmentierung des BO rechts und links konnte in diesem Fall ebenfalls nur unter erschwerten Bedingungen stattfinden. Artefakte entstehen durch eine Störung beim Prozess der Signalerzeugung und Bildberechnung (Hünerbein 2011). Wie in Kapitel 3.4.1 genauer beschrieben, sind hierfür eine Reihe verschiedener Faktoren als Ursache bekannt. Welcher dieser Faktoren Einfluss auf die neue CISS-Aufnahme von Proband 9 nahm ist nicht genau bekannt. Es lässt sich jedoch vermuten, dass es sich um Bewegungsartefakte handelt. Bei allen MRTAufnahmen wurde stets auf die Vermeidung der Artefakt-Entstehung geachtet.

Um das Auftreten möglicher Partialvolumeneffekte zu vemeiden und gleichzeitig eine exakte Darstellung des BO zu gewährleisten, ist neben der Aufnahmesequenz besonders auf die Voxelgröße und Schichtdicke der Aufnahme zu achten (Laubenberger und Laubenberger 1999, Burmeister et al. 2011b, Reith 2011). Bei den vorliegenden Aufnahmen des BO wurden daher kleine Werte für Voxelgröße und Schichtdicke gewählt. Die exakten technischen Einstellungen sind den Kapiteln 5.2.1 und 5.2.2 zu entnehmen.

Bei der manuellen Struktursegmentierung besteht v.a. die Gefahr der ungenauen Segmentierung oder der Segmentierung falscher Strukturen. Daher wird dieser Arbeitsschritt in vielen weiteren Volumetrie-Studien mehrfach bzw. von unterschiedlichen Untersuchern durchgeführt (Fiez et al. 2000, Burmeister et al. 2011b). Dies soll v.a. der Gewährleistung der Inter- und Intraobserver-Reliabilität dienen. In der vorliegenden Studie wurde die manuelle Segmentierung nur einmalig und von nur einem einzigen Untersucher durchgeführt.

Das Verfahren der automatisierten BO-Volumetrie aus MRT-Datensätzen setzt einen am Lehrstuhl für Digitale Bildverarbeitung der Fakultät für Mathematik und Informatik an der Friedrich-Schiller-Universität Jena entwickelten Algorithmus ein. Bisher existieren keine Verfahren zur automatisierten Volumetrie des Bulbus olfactorius. Bei 
der vorliegenden Studie handelt es sich demnach um ein Pilotprojekt, welches derzeit lediglich einen Vergleich mit dem konventionellen Segmentationsverfahren zulässt.

Die Informationen der manuellen Struktursegmentierung wurden zum Training des Erkennungsalgorithmus genutzt. Dabei nimmt der Algorithmus unter dem massiven Einsatz von zufälligen Entscheidungswäldern und der Berechnung mehrerer grundlegender sowie höherrangiger Kontextmerkmale, den sog. Features, eine Differenzierung einzelner Voxel vor. Es soll unterschieden werden, ob einzelne Voxel dem BO oder dessen Umgebung zugeordnet werden. Eine genaue Erläuterung dieses Vorgangs ist Kapitel 5.3.3 zu entnehmen. Um die ungebremste Extraktion von Differenzierungsmerkmalen beim Training des Algorithmus zu verhindern, fanden bei den Entscheidungsbäumen folgende Abbruchkriterien Anwendung:

- Es wird eine maximale Tiefe (Level) festgelegt, welche nicht überschritten werden darf - in den vorliegenden Experimenten ist diese "15". Somit führen maximal 15 binäre Entscheidungen entlang eines Baumpfades vom Wurzelknoten zum Blattknoten. Diese Schranke wird im Allgemeinen selten erreicht, da zuvor meist eines der anderen Abbruchkriterien greift.

- Eine zuvor definierte, minimale Anzahl verschiedener Differenzierungsbeispiele muss in den aktuellen Knoten einfließen. Dies dient der Überprüfung der Sinnhaftigkeit den Knoten erneut aufzuspalten. In den vorliegenden Experimenten wurde die minimale Anzahl auf "50" festgelegt. Fließen nach einem Split weniger als „50“ Beispiele in den Knoten ein, wird dieser nicht weiter aufgeteilt.

- Das Kriterium des Informationsgewinns (sog. information gain) überprüft in jedem Splitknoten, wie gut jener Split war. Es berechnet sich aus der Entropie der Klassenverteilung aller Beispiele „Vor“ dem Split im Vergleich zur Entropie „nach“ dem Split in zwei weiteren Knoten. Die Entropie soll immer kleiner werden. Ist dies nicht mehr der Fall, führt dies zum Abbruch. Im Fall der BOVolumetrie wurde die maximale Anzahl zufälliger Features auf 400 festgelegt, wovon nur das beste Merkmal in den Entscheidungsbaum aufgenommen wird. 
Die 3D-Umgebung eines Voxels der Seitenlänge d zur Feature-Extraktion wurde je nach Aufnahmesequenz unterschiedlich festgelegt. Die Länge $d$ wurde für die Datensätze wie folgt definiert:

- CISS neue Aufnahmen: $d=20$ [Pixel]

- T2 neue Aufnahmen: $d=10$ [Pixel]

- CISS bestehende Aufnahmen: $d=50$ [Pixel]

Je nach Anpassung der Seitenlänge d konnten unterschiedlich genaue Resultate erzielt werden. Die genannten Werte $d$ entsprechen jeweils den Einstellungen, mit welchen die geringste Abweichung für die zugehörige Aufnahmesequenz erzielt wurde. Eine exakte Begründung dieser Beobachtung ist aktuell nicht möglich. Es lässt sich jedoch vermuten, dass die Erkennung der zur Differenzierung extahierten Voxelmuster je nach Umgebungsgröße unterschiedlich gut ist. Die Einbeziehung weiterer Probanden zum Training des Algorithmus könnte einen positiven Effekt auf diese Ergebnisvarianz haben.

Innerhalb der einzelnen Aufnahmeblöcke (10 neue CISS-Datensätze; 10 neue T2Datensätze; 20 bestehende CISS-Datensätze) wurden jeweils eigene Feature-Pools erstellt und zum Training des Algorithmus verwendet. Anschließend fand der Erkennungsalgorithmus mittels einer Leave-One-Out Kreuzvalidierung statt (Molinaro et al. 2005). So wurde beispielsweise für die 10 neuen CISS-Datensätze, der Erkennungsalgorithmus mit 9 Datensätzen trainiert und anschließend auf den einen bis dahin unbekannten Datensatz angewandt. Dieses Verfahren soll verhindern, dass MRT-Datensätze bereits bekannter Probanden vom Algorithmus segmentiert sowie volumetrisch vermessen werden und falsche Volumenwerte nach sich ziehen. Zusätzlich wurde bei der automatisierten Messung des BO-Volumens aller 40 MRTDatensätze eine einheitliche ROI von 100 x 100 [Pixel] festgelegt. Die ROI grenzt einen Bereich der MR-Aufnahme ein, in welchem der BO liegt und der Erkennungsalgorithmus diesen vermisst. Erste Versuche der vorliegenden Methode fanden ohne Festlegung einer ROI statt - beispielhaft in Abbildung 17 dargestellt. Es zeigt, dass einige Bildpunkte der BO-Umgebung, fälschlicherweise dem BO zugeordnet wurden - in Abb. 17 als rote und grüne Markierungen in Orbita-Region dargestellt. Es resultierten falsch-große Volumina des BO. 

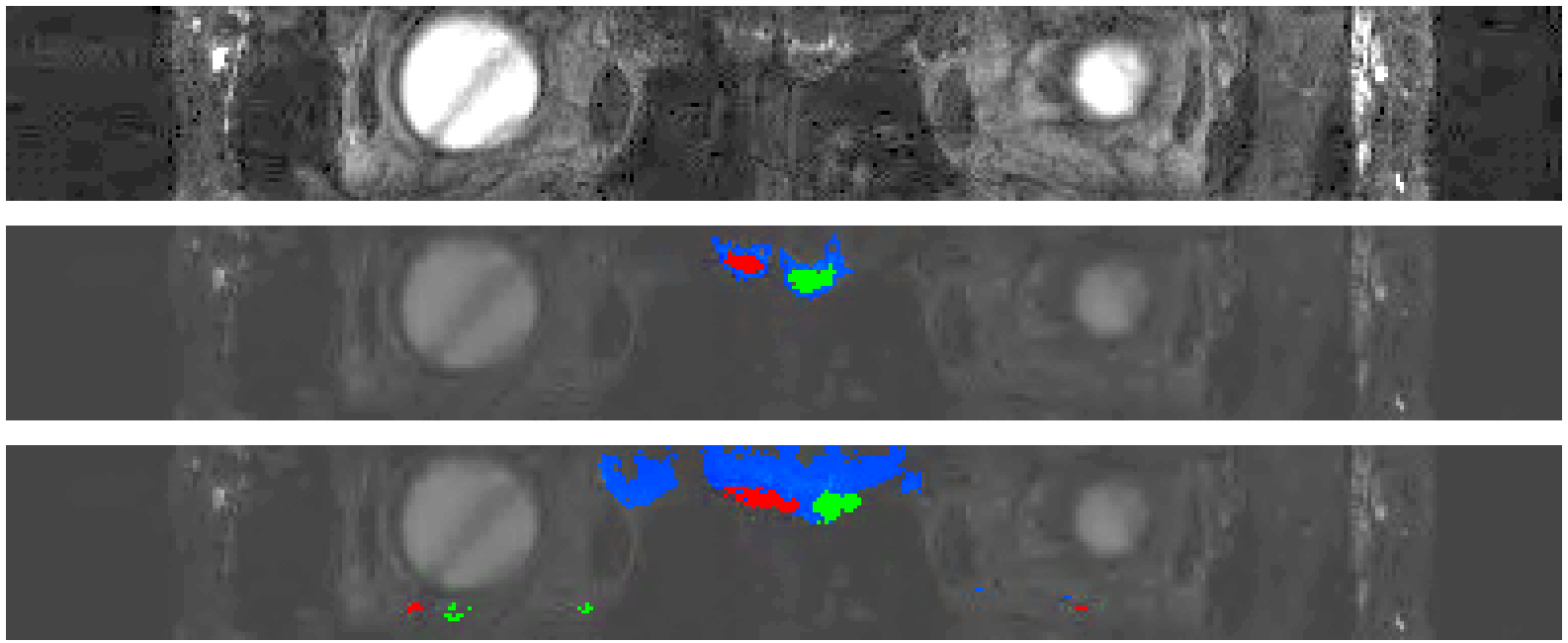

Abb. 17: Originalaufnahme (oben) sowie farblich markiertes Overlay der manuell (Mitte) und vollautomatisiert (unten) segmentierten Strukturen, in vergleichender Darstellung - erste Versuche. Proband Nr. 2, neue CISS MR-Aufnahme, koronare Ansicht, radiologische Konvention. Rot - BO rechts, grün - BO links, blau - Liquor cerebrospinalis sowie vereinzelt falsch differenzierte Bildpunkte.

Nachfolgend entschieden wir uns für die Einführung einer ROI, wie sie auch beim finalen Verfahren der automatisierten BO-Volumetrie Anwendung findet.

\subsection{Diskussion der Ergebnisse}

Das Volumen des BO war in den vergangenen Jahren zentraler Gegenstand zahlreicher Publikationen. Sowohl Yousem et al. als auch Buschhüter et al. stellten fest, dass das Volumen des BO als keine feste Größe anzusehen ist. Vielmehr verändert sich das Volumen im Laufe der Lebensjahre und nimmt bis zum 4. Lebensjahrzehnt zu, bevor es im Anschluss wieder abnimmt (Yousem et al. 1998, Buschhüter et al. 2008). Auch konnte gezeigt werden, dass neben dem Alter vor allem das Geschlecht einen großen Einfluss auf das BO-Volumen hat. So fanden Buschhüter et al. heraus, dass das BO-Volumen bei Frauen tendenziell kleiner ist als das Volumen bei Männern. Die Arbeitsgruppe definierte in ihrer Studie das physiologische Volumen des BO gesunder Probanden als über der 10. Perzentile der von innen untersuchten Bevölkerung. Genauer gesagt sollten Frauen unter 45 Jahren ein minimales BOVolumen von $54 \mathrm{~mm}^{3}$ und Frauen über 45 Jahren ein minimales BO-Volumen von mindestens $43 \mathrm{~mm}^{3}$ aufweisen. Männer unter 45 Jahren sollten ein minimales BOVolumen von $59 \mathrm{~mm}^{3}$ haben, während Männer über 45 Jahren ein minimales BOVolumen von $52 \mathrm{~mm}^{3}$ haben sollten (Buschhüter et al. 2008). Vergleicht man diese 
Aussagen mit den manuell erhobenen Volumenwerten der vorliegenden Studie, so zeigt sich, dass diese Vorgaben vor allem von den 10 neu erhobenen sowie den 20 bestehenden MRT-Aufnahmen in CISS-Sequenz erfüllt werden. Alle in die vorliegende Studie eingeschlossenen Probanden waren zum Untersuchungszeitpunkt unter 45 Jahre alt.

Die exakten quantitativen Volumenwerte der manuellen und automatisierten Messungen sowie deren direkte Gegenüberstellung sind Kapitel 6 zu entnehmen. Die Volumina des automatisierten Verfahrens im Vergleich zum manuellen Verfahren wurden tendenziell als zu groß erkannt. Die besten Volumenwerte konnten mit dem automatisierten Verfahren innerhalb der neu erhobenen MRT-Datensätze in CISSSequenz erzielt werden. Dabei betrug die durchschnittliche Abweichung der automatisierten von den manuellen Volumenwerten für den rechten BO 12,03\% und für den linken BO 22,36\%. Diese Beobachtungen stützen die Erkenntnisse von Burmeister et al., dass die Constructive Interference in Steady State Sequenz die beste MRT-Aufnahmesequenz zur volumetrischen Untersuchung des BO darstellt (Burmeister et al. 2011b). Die Verwendung dieser MRT-Sequenz zur Weiterentwicklung des Verfahrens zur automatisierten MR-Volumetrie des BO ist dringend zu empfehlen.

Eine etwas größere Abweichung der automatisierten von den manuellen Ergebnissen war innerhalb der 20 bestehenden CISS-Datensätzen zu verzeichnen. Diese Beobachtung lässt vermuten, dass trotz gleicher Aufnahmesequenz die Aufnahmequalität ebenfalls einen großen Einfluss auf das vorliegende Verfahren hat. Im Fall unserer Studie konnte durch das vorherige Upgrade des MRT-Scanners von MAGNETOM Trio auf MAGNETOM Prismafit die Aufnahmequalität erheblich verbessert werden.

Zusätzlich untersuchten wir die Möglichkeit der automatisierten BO-Volumetrie aus MRT-Datensätzen in einer T2w TSE 3D Sequenz. Diese Aufnahmesequenz wurde ebenfalls als Möglichkeit zur volumetrischen Untersuchung des BO von Burmeister et al. beschrieben (Burmeister et al. 2011b). Die Ergebnisse der manuellen Volumenmessung der T2w TSE 3D Sequenz zeigen ein deutlich kleineres Volumen des BO im Vergleich zu den manuellen Volumenmessungen des BO in CISS-Sequenz. 
Dies ist vor allem mit einer subjektiv schlechteren Darstellung und somit Segmentierungsmöglichkeit des BO in T2w TSE 3D Sequenz zu begründen. Auch war die Abweichung der automatisierten von den manuellen Ergebniswerten durchschnittlich weitaus größer als dies bei den Ergebnissen der neu erhobenen MRTAufnahmen in CISS-Sequenz zu beobachten war. Als Besonderheit war festzustellen, dass für das automatisierte Verfahren keine Volumenmessung des linken BO von Proband 2 in T2w TSE 3D Sequenz möglich war. Das gemessene Volumen wurde durch den Erkennungsalgorithmus mit $0,00 \mathrm{~mm}^{3}$ angegeben. Für den rechten $\mathrm{BO}$ wurde mittels des automatisierten Verfahrens ein Volumen von 23,66 mm³ berechnet. Die genaue Ursache für diesen Messfehler lässt sich bisher nicht abschließend evaluieren. Dennoch bestärkt diese Beobachtung die Aussage, dass die CISSSequenz besser zur automatisierten BO-Volumetrie geeignet ist. Eventuell verhindert die Einbeziehung einer größeren Anzahl an Probanden in zukünftige Studien die Entstehung von Messfehlern dieser Art.

Wie in Kapitel 5.3.3 erläutert, basiert der Erkennungsalgorithmus auf der Extraktion zufälliger Features zur Differenzierung des BO von dessen anatomischer Umgebung. Zur Überprüfung der Ergebnisvarianz des automatisierten Verfahrens wurde für die 10 neu erhobenen Bilddatensätze in der CISS-Sequenz das Messverfahren mit gleichbleibenden Einstellungen 10x wiederholend durchgeführt. Es lies sich eine gewisse Varianz der quantitativen Werte beobachten, wohingegen die qualitativen Resultate der automatisierten BO-Volumetrie als sehr gut anzusehen sind. Ein Beispiel ist in Abbilbung 14 gezeigt. Es ist naheliegend, dass sich die beobachtete Varianz in zukünftigen Studien durch die Erhöhung der Probandenzahl und somit durch Vergößerung des Feature-Pools minimieren lässt.

Unter Berücksichtigung der geringen Größe der untersuchten anatomischen Struktur, zeichnen sich die qualitativen Ergebnisse des automatisierten Verfahrens, vor allem der neu erhobenen Bilddaten in CISS-Sequenz, durch eine hohe Genauigkeit aus. Sie ermöglichen eine gute Abgrenzung der Bulbi von deren direkten anatomischen Umgebungsstrukturen. Es ist anzunehmen, dass eine weitere Verbesserung der Ergebnisse der automatisierten Segmentierung durch die Erhöhung des Probandenkollektivs möglich ist. 


\section{Schlussfolgerungen und Ausblick}

Zahlreiche Studien der vergangenen Jahre untersuchten die volumetrischen Eigenschaften des Bulbus olfactorius. Diese zeigten, dass eine Vielzahl verschiedener Erkrankungen mit einer Volumenreduktion des BO einhergehen. Beispielsweise konnten Buschhüter et al. im Jahr 2008 die enge Korrelation zwischen dem BOVolumen und Riechvermögen darlegen (Buschhüter et al. 2008). Desweiteren zeigt sich eine Volumenreduktion des $\mathrm{BO}$ bei multiplen Erkrankungen psychiatrischer oder neurodegenerativer Genese, wie Morbus Alzheimer oder Morbus Parkinson (Thomann et al. 2009, Brodoehl et al. 2012). Diese Erkenntnisse sprechen für die klinische Bedeutsamkeit des BO-Volumens. Dabei ist sind sowohl absolute Volumenwerte als auch Volumenänderungen im zeitlichen Verlauf von besonderem Interesse. Zuküntig könnten diese als einfacher Marker zur Erkennung, Diagnosesicherung und Verlaufobjektivierung entsprechender Krankheitsbilder beitragen. Bisher existierte kein Verfahren zur automatisierten Volumenbestimmung des Bulbus olfactorius aus MRT-Datensätzen. Die in der vorliegenden Studie entwickelte Methode konnte erstmalig eine solche automatisierte Volumenbestimmung erfolgreich demonstrieren. Die quantitativen Ergebnisse der automatisierten Messung zeigen je nach Aufnahmesequenz und -einstellungen, verwendetem MRT-Scanner und festgelegten Algorithmuseinstellungen unterschiedlich starke Abweichungen zu den manuellen Messwerten. Die besten Werte für das automatisierte Verfahren konnten innerhalb der neu erhobenen MRT-Datensätze in der CISS-Sequenz erzielt werden. Dies stützt die Erkenntnis von Burmeister et al., dass die Constructive Interference in Steady State Sequenz die beste MRT-Aufnahmesequenz zur volumetrischen Untersuchung des BO darstellt (Burmeister et al. 2011b). Die qualitativen Ergebnisse der Pilotstudie lassen erkennen, mit welch großer Genauigkeit die automatisierte Erkennung, Segmentierung und Vermessung des BO möglich ist. Eine Zusammenschau der quantitativen sowie qualitativen Resultate zeigt, dass trotz der geringen Fallzahl eine automatisierte MR-Volumetrie des Bulbus olfactorius möglich ist. Ebenso besitzt die vollautomatisierte Technik, im Gegensatz zur manuellen Volumenbestimmung, aufgrund ihres geringen Zeitaufwandes und der Untersucherunabhängigkeit das Potential, in die klinischen Routine implementiert zu werden. Es bedarf zukünftig jedoch zunächst weiterer Verbesserungen der angewandten Methode um die Ergebnisvarianz weiter zu minimieren. Hierbei ist vor allem eine Studie unter dem Einsatz einer größeren Anzahl an MRT-Datensätzen verschiedener Probanden zum 
Training des selbstlernenden Algorithmus empfehlenswert. Dies würde dem Erkennungsalgorithmus die Extraktion zusätzlicher Differenzierungsmerkmale erlauben und somit die Erstellung eines vergrößerten Feature-Pools ermöglichen. Gleichzeitig dient eine Studie unter Einschluss eines vergrößerten Probandenkollektivs einer Evaluierung der klinischen Einsetzbarkeit des Verfahrens. Es ist zu empfehlen für die zukünftige Weiterentwicklung des automatisierten Verfahrens ausschließlich MRT-Aufnahmen in der CISS-Sequenz zu berücksichtigen, da diese mit Abstand die besten Ergebniswerte erzielen konnten. Auch ist darüber nachzudenken, die manuelle Struktursegmentierung und anschließende Volumenerhebung durch verschiedene Untersucher bzw. mehrfach durch den selben Untersucher durchzuführen. Dies würde eine noch präzisere Angabe der manuellen Volumenwerte ermöglichen und neben einer besseren Überprüfung der Genauigkeit der automatisierten Ergebniswerte auch eine bessere Basis für den selbstlernen Algorithmus schaffen. 


\section{$9 \quad$ Literatur- und Quellenverzeichnis}

Albrecht J, Wiesmann M. 2006. [The human olfactory system. Anatomy and physiology]. Nervenarzt, 77 (8):931-939.

Ansari KA, Johnson A. 1975. Olfactory function in patients with Parkinson's disease. J Chronic Dis, 28 (9):493-497.

Araneda RC, Kini AD, Firestein S. 2000. The molecular receptive range of an odorant receptor. Nat Neurosci, 3 (12):1248-1255.

Aschenbrenner K, Hummel C, Teszmer K, Krone F, Ishimaru T, Seo HS, Hummel T. 2008. The influence of olfactory loss on dietary behaviors. Laryngoscope, 118 (1):135144.

Aumüller G. 2010. Nase und Nasennebenhöhlen. In: Aumüller G et al, Hrsg. Duale Reihe: Anatomie. Zweite Aufl. Stuttgart: Georg Thieme Verlag KG.

AWMF (Arbeitsgemeinschaft der Wissenschaftlichen Medizinischen Fachgesellschaften e.V.). S2k-Leitlinie 017/050: Riech- und Schmeckstörungen. URL: http://www.awmf.org/uploads/tx_szleitlinien/017-050I_S2k_Riech-und-

Schmeckstörungen_2017-03.pdf, AWMF-Register-Nr. 017/050, Überarbeitung von: 10/2016.

Brabec J, Rulseh A, Hoyt B, Vizek M, Horinek D, Hort J, Petrovicky P. 2010. Volumetry of the human amygdala - an anatomical study. Psychiatry Res, 182 (1):67-72.

Briand L, Eloit C, Nespoulous C, Bezirard V, Huet JC, Henry C, Blon F, Trotier D, Pernollet JC. 2002. Evidence of an odorant-binding protein in the human olfactory mucus: location, structural characterization, and odorant-binding properties. Biochemistry, 41 (23):7241-7252.

Brodoehl S, Klingner C, Volk GF, Bitter T, Witte OW, Redecker C. 2012. Decreased olfactory bulb volume in idiopathic Parkinson's disease detected by 3.0-tesla magnetic resonance imaging. Mov Disord, 27 (8):1019-1025.

Buck LB. 1996. Information coding in the vertebrate olfactory system. Annu Rev Neurosci, 19:517-544.

Burmeister HP, Baltzer PA, Moslein C, Bitter T, Gudziol H, Dietzel M, Guntinas- Lichius O, Kaiser WA. 2011a. Visual grading characteristics (VGC) analysis of diagnostic image quality for high resolution 3 Tesla MRI volumetry of the olfactory bulb. Acad Radiol, 18 (5):634-639.

Burmeister HP, Baltzer PA, Moslein C, Bitter T, Gudziol H, Dietzel M, Guntinas-Lichius O, Kaiser WA. 2011b. Reproducibility and repeatability of volumetric measurements for olfactory bulb volumetry: which method is appropriate? An update using 3 Tesla MRI. Acad Radiol, 18 (7):842-849.

Buschhüter D, Smitka M, Puschmann S, Gerber JC, Witt M, Abolmaali ND, Hummel T. 2008. Correlation between olfactory bulb volume and olfactory function. Neuroimage, 42 (2):498-502. 
Chen CR, Kachramanoglou C, Li D, Andrews P, Choi D. 2014. Anatomy and cellular constituents of the human olfactory mucosa: a review. J Neurol Surg B Skull Base, 75 (5):293-300.

Croy I, Negoias S, Symmank A, Schellong J, Joraschky P, Hummel T. 2013. Reduced olfactory bulb volume in adults with a history of childhood maltreatment. Chem Senses, 38 (8):679-684.

Croy I, Olgun S, Mueller L, Schmidt A, Muench M, Hummel C, Gisselmann G, Hatt H, Hummel T. 2015. Peripheral adaptive filtering in human olfaction? Three studies on prevalence and effects of olfactory training in specific anosmia in more than 1600 participants. Cortex, 73:180-187.

Damm M, Temmel A, Welge-Lussen A, Eckel HE, Kreft MP, Klussmann JP, Gudziol $\mathrm{H}$, Hüttenbrink KB, Hummel T. 2004. [Olfactory dysfunctions. Epidemiology and therapy in Germany, Austria and Switzerland]. HNO, 52 (2):112-120.

Damm M. 2007. [Diagnosis of olfactory disorders--clinical standards and research]. Laryngorhinootologie, 86 (8):565-572.

Debat H, Eloit C, Blon F, Sarazin B, Henry C, Huet JC, Trotier D, Pernollet JC. 2007. Identification of human olfactory cleft mucus proteins using proteomic analysis. $\mathrm{J}$ Proteome Res, 6 (5):1985-1996.

Doty RL. 2009. The olfactory system and its disorders. Semin Neurol, 29 (1):74-81.

Doty RL. 2012. Olfactory dysfunction in Parkinson disease. Nat Rev Neurol, 8 (6):329339.

Fiez JA, Damasio H, Grabowski TJ. 2000. Lesion segmentation and manual warping to a reference brain: intra- and interobserver reliability. Hum Brain Mapp, 9 (4):192211.

Frasnelli J, Hummel T. 2005. Olfactory dysfunction and daily life. Eur Arch Otorhinolaryngol, $262(3): 231-235$.

Frasnelli J, Schuster B, Hummel T. 2007. Interactions between olfaction and the trigeminal system: what can be learned from olfactory loss. Cereb Cortex, 17 (10):2268-2275.

Frings S, Müller F. 2012. Gustatorisches und olfaktorisches System. In: Behrends J C et al, Hrsg. Duale Reihe: Physiologie. Zweite Aufl. Stuttgart: Georg Thieme Verlag KG.

Fröhlich B, Rodner E, Denzler J. 2013. Semantic Segmentation with Millions of Features: Integrating Multiple Cues in a Combined Random Forest Approach. In: Lee KM, Matsushita Y, Rehg JM, Hu Z, Hrsg. Computer Vision - ACCV 2012: 11th Asian Conference on Computer Vision, Daejeon, Korea, November 5-9, 2012, Revised Selected Papers, Part I. Berlin, Heidelberg: Springer Berlin Heidelberg, 218-231.

Goektas O, Schmidt F, Bohner G, Erb K, Ludemann L, Dahlslett B, Harms L, Fleiner F. 2011. Olfactory bulb volume and olfactory function in patients with multiple sclerosis. Rhinology, 49 (2):221-226. 
Gouveri E, Katotomichelakis M, Gouveris H, Danielides V, Maltezos E, Papanas N. 2014. Olfactory dysfunction in type 2 diabetes mellitus: an additional manifestation of microvascular disease? Angiology, 65 (10):869-876.

Gudziol V, Buschhüter D, Abolmaali N, Gerber J, Rombaux P, Hummel T. 2009. Increasing olfactory bulb volume due to treatment of chronic rhinosinusitis--a longitudinal study. Brain, 132 (Pt 11):3096-3101.

Gunbey E, Karli R, Gokosmanoglu F, Duzgun B, Ayhan E, Atmaca H, Unal R. 2015. Evaluation of olfactory function in adults with primary hypothyroidism. Int Forum Allergy Rhinol, 5 (10):919-922.

Handwerker H. O, Schmelz M. 2010. Allgemeine Sinnesphysiologie. In: Schmidt R F et al, Hrsg. Physiologie des Menschen: mit Pathophysiologie. Einunddreißigste Aufl. Berlin Heidelberg: Springer-Verlag.

Hang W, Liu G, Han T, Zhang J, Zhang Q. 2015. [A correlation study on olfactory bulb volumes with ages and olfactory function in healthy adults]. Zhonghua Er Bi Yan Hou Tou Jing Wai Ke Za Zhi, 50 (9):744-748.

Hatt H. 2010. Geschmack und Geruch. In: Schmidt R F et al, Hrsg. Physiologie des Menschen: mit Pathophysiologie. Einunddreißigste Aufl. Berlin Heidelberg: SpringerVerlag.

Herz RS, Cahill ED. 1997. Differential use of sensory information in sexual behavior as a function of gender. Hum Nat, 8 (3):275-286.

Hummel T, Heckmann J G. 2009. Erkrankungen der inneren Nase, der Nasennebenhöhlen, des Mittelgesichts und der vorderen Schädelbasis: Riechstörungen. In: Reiß M, Hrsg. Facharztwissen HNO-Heilkunde: Differenzierte Diagnostik und Therapie. Erste Aufl. Berlin Heidelberg: Springer-Verlag.

Hummel T, Henkel S, Negoias S, Galvan JR, Bogdanov V, Hopp P, Hallmeyer- Elgner S, Gerber J, Reuner U, Haehner A. 2013. Olfactory bulb volume in patients with temporal lobe epilepsy. J Neurol, 260 (4):1004-1008.

Hummel T, Nordin S. 2005. Olfactory disorders and their consequences for quality of life. Acta Oto-Laryngologica, 125 (2):116 - 121.

Hummel T, Smitka M, Puschmann S, Gerber JC, Schaal B, Buschhüter D. 2011. Correlation between olfactory bulb volume and olfactory function in children and adolescents. Exp Brain Res, 214 (2):285-291.

Hünerbein R. 2011. Radiologische Verfahren. In: Reiser M et al, Hrsg. Duale Reihe: Radiologie. Dritte Aufl. Stuttgart: Georg Thieme Verlag KG.

Hüttenbrink KB, Hummel T, Berg D, Gasser T, Hahner A. 2013. Olfactory dysfunction: common in later life and early warning of neurodegenerative disease. Dtsch Arztebl Int, 110 (1-2):1-7, e1.

Kang JH, Kim YC, Kim H, Kim YW, Hur H, Kim JS, Min BS, Kim H, Lim JS, Seong J, Keum KC, Kim NK. 2010. Tumor volume changes assessed by three-dimensional magnetic resonance volumetry in rectal cancer patients after preoperative 
chemoradiation: the impact of the volume reduction ratio on the prediction of pathologic complete response. Int J Radiat Oncol Biol Phys, 76 (4):1018-1025.

Krupa K, Bekiesinska-Figatowska M. 2015. Artifacts in magnetic resonance imaging. Pol J Radiol, 80:93-106.

Kurahashi T, Yau KW. 1993. Co-existence of cationic and chloride components in odorant-induced current of vertebrate olfactory receptor cells. Nature, 363 (6424):7174.

Laubenberger Th, Laubenberger J. Hrsg. 1999. Technik der medizinischen Radiologie: Diagnostik, Strahlentherapie, Strahlenschutz, Für Ärzte, Medizinstudenten und MTRA. Siebte Aufl. Köln: Deutscher Ärzteverlag GmbH.

Lenarz T, Boenninghaus H G, Hrsg. 2012. HNO. Vierzehnte Aufl. Berlin Heidelberg: Springer-Verlag.

Lucassen EB, Turel A, Knehans A, Huang X, Eslinger P. 2016. Olfactory dysfunction in Multiple Sclerosis: A scoping review of the literature. Mult Scler Relat Disord, 6:1-9.

Lüllmann-Rauch R, Hrsg. 2012. Taschenlehrbuch: Histologie. Vierte Aufl. Stuttgart: Georg Thieme Verlag KG.

Malnic B, Godfrey PA, Buck LB. 2004. The human olfactory receptor gene family. Proc Natl Acad Sci U S A, 101 (8):2584-2589.

Malnic B, Hirono J, Sato T, Buck LB. 1999. Combinatorial receptor codes for odors. Cell, 96 (5):713-723.

Mattes RD, Cowart BJ, Schiavo MA, Arnold C, Garrison B, Kare MR, Lowry LD. 1990. Dietary evaluation of patients with smell and/or taste disorders. Am J Clin Nutr, 51 (2):233-240.

Mayr NA, Taoka T, Yuh WT, Denning LM, Zhen WK, Paulino AC, Gaston RC, Sorosky JI, Meeks SL, Walker JL, Mannel RS, Buatti JM. 2002. Method and timing of tumor volume measurement for outcome prediction in cervical cancer using magnetic resonance imaging. Int J Radiat Oncol Biol Phys, 52 (1):14-22.

Mense S. 2010. ZNS - funktionelle Systeme. In: Aumüller G et al, Hrsg. Duale Reihe: Anatomie. Zweite Aufl. Stuttgart: Georg Thieme Verlag KG.

Mesholam RI, Moberg PJ, Mahr RN, Doty RL. 1998. Olfaction in neurodegenerative disease: a meta-analysis of olfactory functioning in Alzheimer's and Parkinson's diseases. Arch Neurol, 55 (1):84-90.

Moberg PJ, Agrin R, Gur RE, Gur RC, Turetsky BI, Doty RL. 1999. Olfactory dysfunction in schizophrenia: a qualitative and quantitative review. Neuropsychopharmacology, 21 (3):325-340.

Molinaro AM, Simon R, Pfeiffer RM. 2005. Prediction error estimation: a comparison of resampling methods. Bioinformatics, 21 (15):3301-3307.

Mueller A, Rodewald A, Reden J, Gerber J, von Kummer R, Hummel T. 2005. Reduced 
olfactory bulb volume in post-traumatic and post-infectious olfactory dysfunction. Neuroreport, 16 (5):475-478.

Negoias S, Croy I, Gerber J, Puschmann S, Petrowski K, Joraschky P, Hummel T. 2010. Reduced olfactory bulb volume and olfactory sensitivity in patients with acute major depression. Neuroscience.

Negoias S, Hummel T, Symmank A, Schellong J, Joraschky P, Croy I. 2016. Olfactory bulb volume predicts therapeutic outcome in major depression disorder. Brain Imaging Behav, 10 (2):367-372.

Negoias S, Pietsch K, Hummel T. 2017. Changes in olfactory bulb volume following lateralized olfactory training. Brain Imaging Behav, 11 (4):998-1005.

Nguyen AD, Pelavin PE, Shenton ME, Chilakamarri P, McCarley RW, Nestor PG, Levitt JJ. 2011. Olfactory sulcal depth and olfactory bulb volume in patients with schizophrenia: an MRI study. Brain Imaging Behav, 5 (4):252-261.

Nitz W R, Runge V M, Schmeets S H, Faulkner W H, Desai N K. Hrsg. 2007. Praxiskurs MRT: Anleitung zur MRT-Physik über klinische Bildbeispiele. Erste Aufl. Stuttgart: Georg Thieme Verlag KG.

Nowarra Ch, Reiter K. 2014. Kernspintomographie. In: Hartmann et al, Hrsg. Fachwissen MTRA: für Ausbildung, Studium und Beruf. Erste Aufl. Berlin Heidelberg: Springer-Verlag.

Nowossadeck S. 2013. Demographic change, people needing long-term care, and the future need for carers. Bundesgesundheitsblatt - Gesundheitsforschung Gesundheitsschutz, 56 (8):1040-1047.

Pause BM, Miranda A, Goder R, Aldenhoff JB, Ferstl R. 2001. Reduced olfactory performance in patients with major depression. J Psychiatr Res, 35 (5):271-277.

Peters JM, Hummel T, Kratzsch T, Lotsch J, Skarke C, Frolich L. 2003. Olfactory function in mild cognitive impairment and Alzheimer's disease: an investigation using psychophysical and electrophysiological techniques. Am J Psychiatry, 160 (11):19952002.

Podlesek D, Leimert M, Schuster B, Gerber J, Schackert G, Kirsch M, Hummel T. 2012. Olfactory bulb volume in patients with idiopathic normal pressure hydrocephalus. Neuroradiology, 54 (11):1229-1233.

Rassow J. 2012. Neurochemie. In: Rassow J et al, Hrsg. Duale Reihe: Biochemie. Dritte Aufl. Stuttgart: Georg Thieme Verlag KG.

Reed DR, Knaapila A. 2010. Genetics of taste and smell: poisons and pleasures. Prog Mol Biol Transl Sci, 94:213-240.

Reith W. 2011. Allgemeine Radiologie. In: Vogl T J et al, Hrsg. Diagnostische und Interventionelle Radiologie. Erste Aufl. Berlin Heidelberg: Springer-Verlag.

Rombaux P, Mouraux A, Bertrand B, Nicolas G, Duprez T, Hummel T. 2006. Olfactory function and olfactory bulb volume in patients with postinfectious olfactory loss. 
Laryngoscope, 116 (3):436-439.

Sakamoto N, Pearson J, Shinoda K et al. 1999. The human basal forebrain. Part I. An Overview. In: Bloom FE, Björklund A, Hökfelt T, Hrsg. Handbook of Chemical Neuroanatomy, Vol. 15: The primate nervous system, Part III. Erste Aufl. Amsterdam: Elsevier Science B.V., 1-13.

Schild D, Restrepo D. 1998. Transduction mechanisms in vertebrate olfactory receptor cells. Physiol Rev, 78 (2):429-466.

Schünke M, Schulte E, Schumacher U, Voll M, Wesker, K, Hrsg. 2009. PROMETHEUS - LernAtlas der Anatomie: Kopf, Hals und Neuroanatomie. Zweite Aufl. Stuttgart: Georg Thieme Verlag KG.

Seo HS, Jeon KJ, Hummel T, Min BC. 2009. Influences of olfactory impairment on depression, cognitive performance, and quality of life in Korean elderly. Eur Arch Otorhinolaryngol, 266 (11):1739-1745.

Sickert S, Rodner E, Denzler J. 2016. Semantic volume segmentation with iterative context integration for bio-medical image stacks. Pattern Recognition and Image Analysis, 26 (1):197-204.

Stevenson RJ. 2010. An initial evaluation of the functions of human olfaction. Chem Senses, 35 (1):3-20.

Temmel AF, Quint C, Schickinger-Fischer B, Klimek L, Stoller E, Hummel T. 2002. Characteristics of olfactory disorders in relation to major causes of olfactory loss. Arch Otolaryngol Head Neck Surg, 128 (6):635-641.

Thomann PA, Dos Santos V, Toro P, Schonknecht P, Essig M, Schroder J. 2009. Reduced olfactory bulb and tract volume in early Alzheimer's disease--a MRI study. Neurobiol Aging, 30 (5):838-841.

Tittgemeyer M, von Cramon DY. 2004. MRT-basierte Morphometrie. Der Nervenarzt, 75 (12):1172-1178.

Trepel M, Hrsg. 2012. Neuroanatomie: Struktur und Funktion. Fünfte Aufl. München: Elsevier $\mathrm{GmbH}$, Urban \& Fischer Verlag.

Tsutsumi S, Ono H, Yasumoto Y. 2017. Visualization of the olfactory nerve using constructive interference in steady state magnetic resonance imaging. Surg Radiol Anat, 39 (3):315-321.

Turetsky BI, Moberg PJ, Yousem DM, Doty RL, Arnold SE, Gur RE. 2000. Reduced olfactory bulb volume in patients with schizophrenia. Am J Psychiatry, 157 (5):828830.

Wang J, You H, Liu JF, Ni DF, Zhang ZX, Guan J. 2011. Association of olfactory bulb volume and olfactory sulcus depth with olfactory function in patients with Parkinson disease. AJNR Am J Neuroradiol, 32 (4):677-681.

Weinstock RS, Wright HN, Smith DU. 1993. Olfactory dysfunction in diabetes mellitus. Physiol Behav, 53 (1):17-21. 
Witt M. und Hansen A. 2008. Strukturelle und funktionelle Grundlagen des Riechens. In: Hummel T und Welge-Lüssen A, Hrsg. Riech- und Schmeckstörungen: Physiologie, Pathophysiologie und therapeutische Ansätze. Erste Aufl. Stuttgart: Georg Thieme Verlag KG.

Yousem DM, Geckle RJ, Bilker W, McKeown DA, Doty RL. 1996. MR evaluation of patients with congenital hyposmia or anosmia. AJR Am J Roentgenol, 166 (2):439443.

Yousem DM, Geckle RJ, Bilker WB, Doty RL. 1998. Olfactory bulb and tract and temporal lobe volumes. Normative data across decades. Ann N Y Acad Sci, 855:546555. 


\section{Anhang}

\subsection{Danksagung}

Ich möchte allen, die mich in der Zeit meiner Promotion an der Klinik für Hals-, Nasenund Ohrenheilkunde des Universitätsklinikums Jena auf unterschiedlichste Weise unterstützt haben, hiermit meinen herzlichen Dank aussprechen.

Mein besonderer Dank gilt Herrn Priv.-Doz. Dr. med. habil. Thomas Bitter für die Bereitstellung des Themas und die breite Unterstützung bei der Planung und Ausführung der Arbeit. Insbesondere danke ich auch für die fachlichen Anregungen und Ratschläge bei der Erstellung der Dissertationsschrift.

Außerdem gilt mein besonderer Dank Herrn Dipl.-Inf. Sven Sickert vom Lehrstuhl für Digitale Bidverarbeitung der Fakultät für Mathematik und Informatik an der FriedrichSchiller-Universität Jena für seine geduldige Unterstützung bei der Auswertung der MRT-Datensätze wie auch bei der Beantwortung fachlicher Fragen.

Herrn Prof. Dr. med. Guntinas-Lichius danke ich für die Möglichkeit, in seiner Klinik promovieren und die Ressourcen der Klinik für Hals-, Nasen- und Ohrenheilkunde des Universitätsklinikums Jena nutzen zu dürfen.

Herrn Prof. Dr.-Ing. Denzler danke ich für die Unterstützung durch den Lehrstuhl für Digitale Bildverarbeitung der Fakultät für Methematik und Informatik an der FriedrichSchiller-Universität Jena.

Mein weiterer Dank gilt Prof. Dr. med. Teichgräber sowie allen Mitarbeiterinnen und Mitarbeitern des Instituts für Diagnostische und Interventionelle Radiologie für die Hilfe bei den MRT-Messungen.

Ich danke allen Freunden und Probanden, die an meiner Studie teilnahmen und so meine Promotion erst ermöglichten.

Meiner Familie und besonders Eltern Volker und Marion Schmitt danke ich für die Ermöglichung meines Studiums und Promotion an der Friedrich-Schiller-Universität 
Jena sowie deren Unterstützung und Rückhalt zu jeder Zeit. Ebenso danke ich meiner Schwester Alisa Schmitt sowie meiner Freundin Lena Wucherpfennig für die zahlreichen Ermutigungen und die liebevolle Unterstützung in den letzten Jahren. Dies gilt im Weiteren auch für meine engsten Freunde und Kommilitonen. 


\subsection{Ehrenwörtliche Erklärung}

Hiermit erkläre ich, dass mir die Promotionsordnung der Medizinischen Fakultät der Friedrich- Schiller-Universität bekannt ist,

ich die Dissertation selbst angefertigt habe und alle von mir benutzten Hilfsmittel, persönlichen Mitteilungen und Quellen in meiner Arbeit angegeben sind,

mich folgende Personen bei der Auswahl und Auswertung des Materials sowie bei der Herstellung des Manuskripts unterstützt haben: Priv.-Doz. Dr. med. habil. Thomas Bitter und Dipl.-Inf. Sven Sickert,

die Hilfe eines Promotionsberaters nicht in Anspruch genommen wurde und dass Dritte weder unmittelbar noch mittelbar geldwerte Leistungen von mir für Arbeiten erhalten haben, die im Zusammenhang mit dem Inhalt der vorgelegten Dissertation stehen,

dass ich die Dissertation noch nicht als Prüfungsarbeit für eine staatliche oder andere wissenschaftliche Prüfung eingereicht habe und

dass ich die gleiche, eine in wesentlichen Teilen ähnliche oder eine andere Abhandlung nicht bei einer anderen Hochschule als Dissertation eingereicht habe.

Ort, Datum

Niclas Schmitt 
Teile dieser Arbeit wurden veröffentlicht:

Schmitt N, Sickert S, Denzler J, Guntinas-Lichius O, Bitter T. 2018.

Automatisierte MR-Volumetrie des Bulbus olfactorius. Poster mit Vortrag 89. Jahresversammlung der Deutschen Gesellschaft für Hals-Nasen-Ohren-Heilkunde, Kopf- und Hals-Chirurgie e.V., Lübeck.

https://www.thieme-connect.de/products/ejournals/abstract/10.1055/s-0038-1639838 